DIW BERLIN

Discussion

Papers

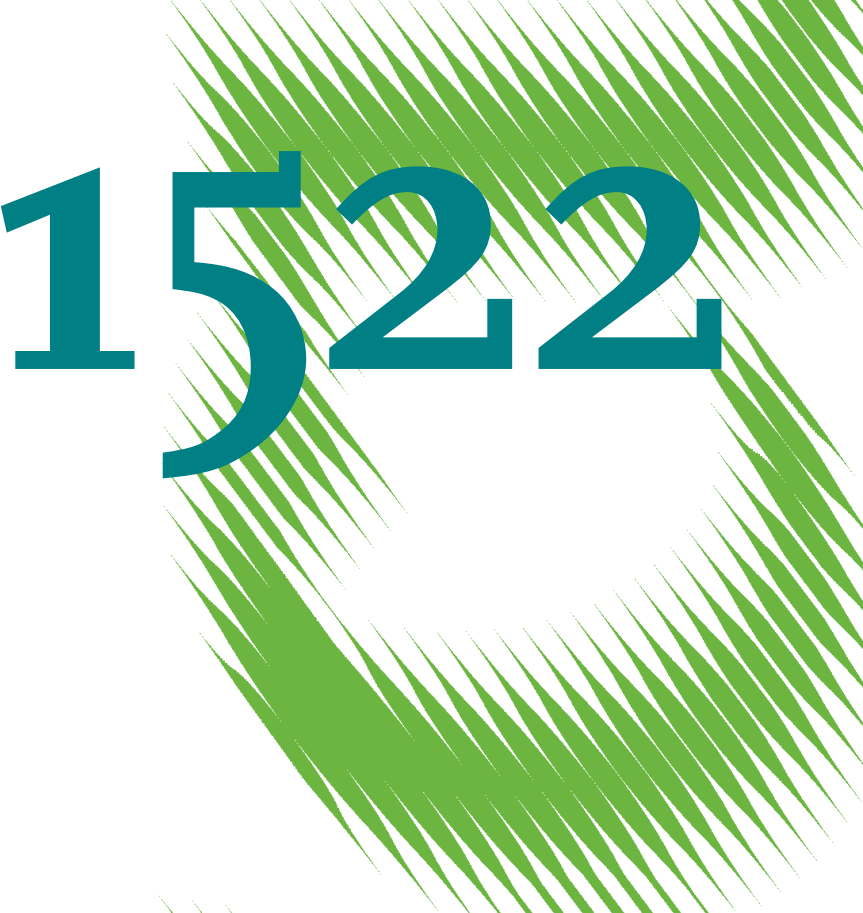

Cross-Country Estimates of Employment and Investment in Organisational Capital: A Task-Based Methodology Using the PIAAC Database 
Opinions expressed in this paper are those of the author(s) and do not necessarily reflect views of the institute.

IMPRESSUM

(C) DIW Berlin, 2015

DIW Berlin

German Institute for Economic Research

Mohrenstr. 58

10117 Berlin

Tel. +49 (30) $89789-0$

Fax +49 (30) $89789-200$

http://www.diw.de

ISSN electronic edition 1619-4535

Papers can be downloaded free of charge from the DIW Berlin website:

http://www.diw.de/discussionpapers

Discussion Papers of DIW Berlin are indexed in RePEc and SSRN:

http://ideas.repec.org/s/diw/diwwpp.html

http://www.ssrn.com/link/DIW-Berlin-German-Inst-Econ-Res.html 


\title{
Cross-Country Estimates of Employment and Investment in Organisational Capital: A Task-Based Methodology Using the PIAAC Database
}

\author{
Marie Le Mouel*, Mariagrazia Squicciarini^
}

(*) DIW Berlin, German Institute for Economic Research and OECD, Economic Analysis and Statistics Division (EAS).

(^) OECD, Economic Analysis and Statistics Division (EAS).

Acknowledgements: We are grateful to Mary O'Mahony, Sebastien Miroudot, the OECD-PIAAC team, the country delegates to the OECD Working Party on Industry Analysis (WPIA) and the participants of the EUfunded SPINTAN project for helpful comments and for providing feedback on earlier versions of the paper. The existing discussion paper is also available as an OECD Science, Technology and Industry Working Paper, number 2015/08, doi: 10.1787/5jrs3smfgcjb-en. The usual caveats apply. 


\begin{abstract}
This work proposes a task-based methodology for the measurement of employment and investment in organisational capital (OC) in 20 OECD countries. It builds on the methodology of Squicciarini and Le Mouel (2012) and uses information from the OECD Programme for the International Assessment of Adult Competencies (PIAAC). OC is defined as firm-specific organisational knowledge resulting from the performance of tasks affecting the long-term functioning of firms, such as developing objectives and strategies; organising, planning and supervising production; and managing human resources. Occupations contributing to the generation of $O C$ are identified using distribution-based criteria and clustering analysis. Crosscountry heterogeneity in OC-related occupations emerges: while 20 occupational classes of the International Standard Classification of Occupations (ISCO 2008) are on average identified as being OC-related, country-specific values range between 14 (in Korea) and 24 occupations (in Poland). A core group of managerial occupations are consistently identified as OC occupations across countries, whereas differences arise in the selection of professionals and associate professionals in science and engineering, health, education, and business administration. Inhouse investment in OC for the 2012 is measured à la Corrado, Hulten and Sichel (2009), as 20\% of wages paid to OC-related occupations. Estimates at the aggregate level suggest the share of OC occupations in total employment to represent between 9.5\% (Denmark) to 26\% (United Kingdom), with an average of $16 \%$. Total investment in OC, as a share of value-added, ranges from $1.4 \%$ in the Czech Republic to $3.7 \%$ in the United Kingdom, with an average $2.2 \%$ across all countries. Managers appear to account for less than half of total employment and investment in $O C$, and total investment in $O C$ is higher in services than in manufacturing. Experimental estimates of investment in $\mathrm{OC}$ by firm class size and by the private and public sector and are also proposed. In the services sector, small firms account for on average half of OC investment in that sector, while in manufacturing, $45 \%$ of OC investment comes from large firms. Finally, with only few exceptions, investment in $O C$ appears to be higher in the public sector than in the private sector.
\end{abstract}

Keywords: Organisational capital, intangible capital, tasks, employment, investment, Programme for the International Assessment of Adult Competencies (PIAAC)

JEL classification: D24 


\section{EXECUTIVE SUMMARY}

The present paper seeks to validate the methodology first proposed in Squicciarini and Le Mouel (2012) to measure employment and investment in organisational capital (OC). It capitalised on the definition of $\mathrm{OC}$ as the firm-specific organisational knowledge resulting from the performance of tasks affecting the long-term functioning of firms. The tasks considered involve: developing objectives and strategies; organising, planning and prioritising work; building teams, matching employees to tasks, and providing training; supervising and coordinating activities; and communicating across and within groups to provide guidance and motivation.

This definition is operationalised using survey information on tasks performed in the workplace. Building on Squicciarini and Le Mouel (2012) who use the ONET database and perform the analysis on the United States, the present paper adds an international dimension by using the OECD Programme for the International Assessment of Adult Competencies (PIAAC) data. The objective of this analysis is to test, firstly, the extent to which the task-based methodology is sensitive to the choice of data source and, secondly, if there is important crosscountry heterogeneity in management practices and organisational arrangements, in line with the evidence of Bloom and Van Reenen (2007).

Occupations who contribute to the generation and accumulation of $\mathrm{OC}$ are identified using two separate criteria. Firstly, the top quartile of occupations who perform OC-related tasks on a consistent basis are selected. Secondly, clustering analysis identifies groups of occupations whose daily activities are homogenous and high OC content groups are extracted from this list. The sensitivity of this selection to the initial list of tasks included in the OC bundle is also tested.

Results suggest that on average 20 broad occupational classes of the International Standard Classification of Occupations (ISCO 2008) are identified as OC-related in each country. This varies across countries and spans from 14 occupations in Korea to 24 occupations in Poland, supporting the hypothesis of cross-country heterogeneity in OC. Despite these differences, a core group of managerial occupations are consistently identified as OC occupations across countries. Differences arise in the selection of professionals and associate professionals in science and engineering, health, education, and business administration.

The importance of these occupations in the economy can be estimated using the labour force participation and earnings information contained in the PIAAC dataset. The second part of the analysis thus estimates the importance of OC-related employment and the size of in-house investment in $\mathrm{OC}$ at the aggregate level and according to a number of disaggregations. In-house investment in OC follows the definition of Corrado, Hulten and Sichel (2009) and is measured as $20 \%$ of wages paid to OC-related occupations. At the aggregate level, the share of all OC occupations in total employment represents between $9.5 \%$ in Denmark to $26 \%$ in the United 
Kingdom, with an average of $16 \%$. Total investment in OC, as a share of value-added, ranges from 1.4\% in the Czech Republic to 3.7\% in the United Kingdom, with an average $2.2 \%$ across all countries. Splitting the share attributable to managers from that attributable to non-managerial OC occupations reveals that managers account for less than half of total employment and investment in OC. This suggests that measuring OC by looking only at managers is likely to lead to an underestimation of the resources devoted to this asset.

The wealth of information contained in the PIAAC database allows for a detailed breakdown of $O C$ employment and investment. Results suggest that total investment in $O C$ is higher in services than in manufacturing. In the services sector, on average half of investment in OC comes from small firms, while in manufacturing, $45 \%$ of investment in OC comes from large firms. Finally, the importance of $O C$ investment in the public sector is investigated. With only few exceptions, investment in $\mathrm{OC}$ is higher in the public sector than in the private sector.

These results bring a new perspective on the importance of $\mathrm{OC}$ in the economy. They highlight large country and sectoral differences in the intensity of OC investment, which have not yet been documented. In addition, the role of $\mathrm{OC}$ in growth, as evidenced in previous growth accounting exercises, would need to be revised to take into account the size of OC investment once non-managerial OC-related occupations are included. Finally, these updated estimates of OC investment can be used to analyse its role with respect to skill use and mismatch, its impact on the routinisation of tasks and resulting polarisation of wage distribution, and its role in integrating and upgrading global value chains (GVC).

\section{Introduction}

Organisational capital (OC) is an elusive concept whose importance is nevertheless widely acknowledged, as it is found to correlate positively with firm performance and productivity (e.g. Hansen and Wernerfelt, 1989; Brynjolfsson et al., 2002). The numerous definitions that exist generally emphasise the knowledge and information-based systemic nature of organisational capital, its role in linking tangible and intangible assets, and its strategic importance (e.g. Prescott and Visscher, 1980; Black and Lynch, 2005).

Several studies have engaged in quantifying firms' investments in this important type of knowledge-based capital (KBC), in uncovering the relationship linking investment in $\mathrm{OC}$ and in other types of KBC to differences in firms' performance (e.g. Aral and Weill, 2007), and in assessing the extent to which investment in KBC shapes entrepreneurial dynamics and productivity. These studies often follow an expenditure-based approach and rely on selling, general and administrative (SGA) expenses, or on managerial wages data to proxy investment in OC.

Examples are Papanikolaou and Eisfeldt (2009), who use SGA figures and find that firms having a higher ratio of $O C$ to book assets are more productive, have higher Tobin's $Q$, higher risk adjusted returns and higher levels of executive compensation. Lev et al.'s (2009) SGA-based 
figures also suggest organisational capital to be positively related to executive compensation, and to long term operating and stock performance. Corrado, Hulten and Sichel (2005, 2009, henceforth CHS) rely on managers' compensation and on the revenues of the management consulting industry to proxy own account and purchased OC respectively, and investigate the role of KBC in driving aggregate US productivity growth.

While significantly contributing to a better understanding and measurement of KBC in general, and of $O C$ in particular, these approaches nevertheless do not provide a clear definition of what organisational capital is or does, and may overestimate (in the case of SGA) or underestimate (in the case of CHS 2005, 2009) such investment. On the one hand, SGA expenses encompass a wider category of assets than OC alone. SGA expenditures, which are used by e.g. Lev et al. (2009) to proxy the outlays related to building OC, in fact include expenses such as training, advertising and information technology (IT) that other scholars, e.g. CHS $(2005,2009)$, identify as separate KBC items. On the other hand, the literature has long suggested that firms' organisational capabilities reside in a number of occupations including but not limited to managers.

The increasing prevalence of distributed leadership (von Krogh et al. 2012), coupled with jobs being interpreted as organisational building blocks arising out of the bundles of tasks performed under different administrative job titles (Cohen, 2013) call for the use of task-based rather than occupational title-based criteria when identifying and measuring investment in OC (Prescott and Visscher, 1980; Black and Lynch, 2005).

The present work capitalises on the task-based approach first presented in Squicciarini and Le Mouel (2012) and proposes a definition of organisational capital and a measurement approach that builds on the organisational, management and economics literatures. It defines organisational capital as the firm-specific organisational knowledge resulting from the performance of tasks affecting the medium and long-term functioning of firms. The tasks considered involve, to varying degrees: developing objectives and strategies; organising, planning and prioritising work; building teams, matching employees to tasks, and providing training; supervising and coordinating activities; and communicating across and within groups to provide guidance and motivation. In Squicciarini and Le Mouel (2012) this task-based definition was operationalised using Occupational Information Network (O*NET) data to identify the occupational categories that most perform OC-related tasks, and Current Population Survey (CPS) and Occupational Employment Statistics (OES) data to calculate investment in OC. This was done both at the macro and at the 2-digit industry level for the United States.

The task-based methodology of Squicciarini and Le Mouel (2012) is here implemented on novel cross-country data available in the OECD Programme for the International Assessment of Adult Competencies (PIAAC) survey. This is done to validate the results first obtained using O*NET data and to gain further insights on the extent to which organisational knowledge is generated by managers and other occupations and about the possible differences that may exist across countries. 
To this end information relating to tasks performed at work by different occupations, available in the PIAAC survey for 20 countries, is exploited to identify those occupations carrying out OCrelated tasks to the highest extent. In total, around 20 broad occupational classes of the International Standard Classification of Occupations (ISCO 2008), including managerial, professional and associate professional occupations in business administration, science and engineering, health, and education, are identified as contributing to generate and accumulate own-account ${ }^{1}$ OC.

Secondly, exploiting the cross-country nature of the PIAAC dataset, this analysis tests the 'homogeneity' assumption implicitly made by the OC measurement literature whereby crosscountry estimates, when they exist, are based on methodologies devised for and tested on one country only - typically the United States - and then replicated on other countries (e.g. INTANInvest estimates). Doing so entails implicitly assuming that countries are broadly similar in their industrial structures and framework conditions, and that organisational practices and investment are to a great extent homogeneous across countries. However, recent literature, including a number of studies led by Bloom and Van Reenen (e.g. Bloom and Van Reenen, 2007, 2010; Bloom et al., 2012), provides compelling evidence on the existence of cross-country differences in management practices and organisational arrangements. The PIAAC data offer a unique opportunity to explore the country-specific nature of OC.

Thirdly, OC-related employment and investment figures for the year 2012 are estimated using the labour force participation and earnings information contained in the PIAAC survey. This is done following existing definitions of own-account or in-house investment in OC (especially from CHS), whereby $20 \%$ of the earnings of OC-related occupations is considered own-account investment in OC. The resulting estimates suggest that at the aggregate level, employment in all OC-related occupations and total OC investment figures thus obtained are on average 2.5 times higher than those resulting from considering managerial occupations only. This implies that estimates based on managers might underestimate OC. Also, thanks to the wealth of information contained in the PIAAC database, OC employment and investment figures have been estimated at levels which had not been hitherto considered due to data limitations: by industry, by firm size (micro firms; small and medium enterprises; and large firms), and by the public or private nature of the firm.

The remainder of this paper gives a brief survey of the literature related to measuring OC, followed by a discussion of the proposed definition of organisational capital and of the way in which it is operationalised - discussion that builds importantly on Squicciarini and Le Mouel (2012). The data and analytical methodology used to select the relevant OC-related occupations using PIAAC data are then presented, followed by the estimated economy-wide and sectoral level investment figures. The final section discusses how these novel estimates compare with existing ones, summarises the main contributions of the paper, and highlights some limitations and possible avenues of future research.

1. Differently from Squicciarini and Le Mouel (2012), the present work focuses on own-account investment in OC, thus overlooking the purchased component and the depreciation of investments in organisational capital. 


\section{Defining organisational capital}

The very nature of $O C$ has made it one of the more challenging $K B C$ assets to quantify convincingly. This is reflected by the different, albeit often complementary, definitions and measurement approaches that have emerged in economics, organisation science, management, and accounting.

OC has been defined as the firm-specific information that affects the production possibility set and is augmented through output-related learning processes (Prescott and Visscher, 1980); the know-how needed to create systems of production combining human skills and physical capital (Evenson and Westphal, 1995); and the ability to integrate individual members' specialised knowledge, which serves as the basis upon which firms establish their long-term strategies (Grant, 1996). Black and Lynch (2005) further highlight the importance of OC-related firm practices like workforce training, 'employee voice' and work design, and their relation with higher productivity.

The economics literature has often modelled $O C$ as a firm specific information asset, whose conceptualisation rests on a notion of the firm that goes beyond the representative production function. Prescott and Visscher (1980) argue that OC is a type of business knowledge which is able to affect a firm's production possibility set and that gets accumulated jointly with output. OC's main information-related components concern employee and task characteristics; the quality of their match, and the quality of the match of employees to teams; and the knowledge embodied in employees in the form of firm-specific training. Such knowledge, they argue, represents the source of a firm's comparative advantage to create and maintain revenue streams. Prescott and Visscher (1980) and Bailey et al. (2001) further suggest that the following sets of tasks are essential in generating a firm's organisational knowledge: developing objectives and strategies; organising, planning and prioritising work; building teams, matching employees to tasks, and providing training; supervising and coordinating activities; communicating across and within groups to provide guidance and motivation.

The approach to OC proposed by Prescott and Visscher (1980) can be found in a number of models, including: firms' internal learning processes and the creation and accumulation of this KBC (Rosen, 1972); the difficulty of matching employees to jobs and the resulting employee turnover dynamics (Jovanovic, 1979); the impact of investment in this KBC on firm growth and size distribution (Prescott and Visscher, 1980); and more recently, the rents accruing to firm owners from the returns on OC (Atkeson and Kehoe, 2005).

The managerial and organisational science literature has conversely tended to emphasise the role of OC and of organisational capabilities as sources of competitive advantage, and as key firm-specific resources. As Teece et al. (1997) highlight, earlier explanations of firm-specific rents were mainly based on industrial organisation theories related to market dynamics like the ease of entry into a market and bargaining power, or on game theoretic approaches modelling the strategic decisions of players (e.g. predatory pricing to deter entry).

Conversely, more recent explanations of sustained competitive advantage focus on the ability of firms to exploit scarce and non-imitable firm-specific resources. This Resource Based View (RBV) 
of the firm underlines the need to understand a firm's capabilities in terms of the organisational structure and managerial processes that underpin its productive activity, rather than in terms of balance sheet items. Teece et al. (1997) further argue that in a dynamic context of Schumpeterian creative destruction, a firm's ability to react and adapt to an ever changing business environment and to up-grade its activity in a global value-chain context rests mainly on its flexible organisational structure and its superior managerial knowledge and qualities. This organisational knowledge emerges from interactions between individuals within the firm and is formalised and articulated into routines by specific functions within the organisation (Nonaka, 1994). Looking beyond the role of central, upper-echelon leadership, von Krogh et al. (2012) propose a model of organisational knowledge creation that emphasises the distributed nature of organisational knowledge within a firm.

In this respect, Aral and Weill's (2007) study of IT assets and organisational capability shows that differences in performance emerge when firms invest in both assets jointly. Kapoor and Adner (2011) highlight the importance of a firm's organisational structure for its ability to manage technological change, while Nocke and Yeaple (2014) argue that OC can affect firms' export status and product diversification through its effect on marginal costs.

Recently, sociological approaches to organisation theory have further set aside the standard economic notion of rational profit-seeking individuals and emphasised the interconnectedness of actors and the power struggles involved in their relationships (Lounsbury and Ventresca, 2003). In particular, embeddedness has emerged as a key concept in the analysis of organisations. It places the focus on the network of relationships within which a firm's employees are engaged, or embedded, and that allow for relevant knowledge to be shared and integrated both in formal organisations and in the dispersed practices of individuals (Agterberg et al., 2010).

Whether aimed at investigating structural embeddedness, i.e. organisational knowledge contained in the network as a whole, or relational embeddedness, i.e. individuals and their relations, social network analysis has become increasingly popular in many fields, and finds a natural application in the context of organisation theories (Borgatti and Foster, 2003). Its use has led to research on management performance and impact on a number of dynamics, including innovation (Moran, 2005), job turnover (Allen, 2006; Clinton et al., 2012), individual career paths (Ng and Feldman, 2009), and perceived organisational support (Hayton et al, 2012).

The concepts of $\mathrm{OC}$ and embeddedness have sometimes been interpreted to include a firm's external network of suppliers and customers and used to analyse joint ventures and inter-firm alliances (see Gulati, 1998 for a review; and Gulati, 2007). In particular, the specific operational challenges faced by multinational companies have spurred important research on the interaction of a firm's internal and external networks and the possibility to combine local networks with transnational cultures and practices (Meyer et al., 2011 and Agterberg et al., 2010). These notions are likely to be closely linked, as managing more complex networks of suppliers and customers might indeed require a deeper organisational apparatus. 
Scholars concerned with the definition and measurement of OC (e.g. Johnson, 1999; Bounfour, 2010) however generally tend to distinguish OC from relational capital, intended as the set of relationships a firm has with its suppliers and customers, and to use different approaches to measuring them.

Finally, a broad literature - from psychology to finance - underlines the positive relationship between performance on the job and workforce endowments in terms of skills and competencies that are relevant to the tasks to be accomplished (e.g. Kaplan et al., 2012; Ng and Feldman, 2009). Consensus seems to exist about the fact that employee skills and abilities, as well as other characteristics, are related to outcomes at both the level of the individual employee and of the firm (see Ployhart and Moliterno, 2011, for a discussion). Also, recent survey-based evidence from Bloom et al. (2012) further confirms management quality to be related to both managers' and employees' educational levels.

The concepts and lessons drawn from the various fields above lend support to a view of OC that emphasises its key role in the activity of firms and in their success: OC consists of knowledge, know-how and business practices, and is embedded in a firm's workforce. However, while much literature discusses what is meant by OC, attempts to measure how much $\mathrm{OC}$ is generated and accumulated are less apparent.

\section{Measuring organisational capital}

\section{Existing approaches to measuring organisational capital}

Existing OC measurement-related studies can be broadly subdivided into three main groups, depending on the approach followed. The first group relies on non-monetary survey-based measures and attempts to capture the adoption, presence and quality of organisational and managerial practices. The second group is concerned with obtaining monetary estimates of the value of organisational practices in terms of output, and in particular of increased firm performance. Finally, a third group of studies measures investment in $O C$ by means of assessing the value of the inputs devoted to building up such KBC.

Studies carried out in the early 2000s rely on a somewhat narrow definition of OC, intended mainly as organisational change aimed at introducing novel work practices such as decentralisation (Caroli and Van Reenen, 2001), High Performance Work Systems (HPWS, see Bailey et al., 2001), autonomy over work tasks, and the opportunity to communicate with employees outside the work group. Analysis relying on such a definition has focused on learning organisations giving firm's employees the opportunity to use and develop their skills and knowledge (e.g. Greenan, 2012); and on "new" organisation features, such as flat hierarchy, empowered workers, self-governing teams, use of temporary structures and lateral communications enabled by the adoption of ICTs (see, e.g. van Alstyne, 1997; Birkinshaw and Hagstrom, 2000; and Hales, 2002).

Although narrow, the above definition of $O C$ makes measurement of organisational practices tractable, and significant efforts have been made in designing business surveys aiming to assess 
the implementation and quality of organisational practices (see e.g. Black and Lynch, 2005, for a survey). These measures of $\mathrm{OC}$ have been widely used to understand the impact of organisational practices and organisational change on firm performance (Black and Lynch 2001, Miyagawa et al. 2010); on the demand for skills (Caroli and Van Reenen, 2001); on wage levels, wage inequalities and employment dynamics (Bailey et al. 2001; and Black, Lynch and Krivelyova, 2004); and about the determinants of management quality (Bloom and Van Reenen, 2007).

Noteworthy in this respect is the line of work of Bloom et al. (2012), who have designed and carried out a survey of middle level managers in over 10000 organisations in twenty countries to investigate management practices related to processes, monitoring, targets and incentives, with the aim of assessing overall management quality at the firm level.

In a second group of studies, OC is defined as a firm-specific knowledge asset, and its effect on measures of firm performance such as gross output, sales and revenues is quantified, in a similar fashion to other balance sheet assets. Such literature generally relies on the estimation of firm level production functions, as in Lev and Radhakrishnan (2005) and Lev et al. (2009) for the United States, Miyagawa and Kim (2008) for Japan, and Ludwig and Sadowski (2009) for Germany. Lev et al. (2009), for instance, estimate firms' OC in terms of profit surplus accruing from increased revenue and decreased costs, as compared to the predicted profits that would be obtained in the absence of such KBC. To this end, investment in $\mathrm{OC}$ is proxied by firms' spending on SGA expenses, whereas predicted profits are derived from industry-level figures.

Miyagawa and Kim (2008) conversely estimate OC in terms of excess returns to investment in complementary assets such as R\&D and advertising. This methodology is generally followed to estimate the value - at both the firm and the aggregate level - of bundles of intangibles. SGA expenses can in fact be used as firm-level proxies for investment in many types of KBCs, as they include R\&D, marketing and software expenditures, as well as management fees (Che, 2009). However, relying on a production function-based approach to estimate Total Factor Productivity (TFP) makes it difficult to determine the mechanism picked up in the residual, i.e. whether it is the effect of $\mathrm{OC}$, or of $\mathrm{KBC}$ more broadly, or even of other factors such as technological progress.

A third approach to measuring $\mathrm{OC}$ relies on quantifying the value of the resources used to build it and has been suggested by CHS. The authors assume own-account OC to amount to the time that managers spend on developing a firm's business model and its corporate culture. They estimate it to correspond to $20 \%$ of executives' time, as managers are assumed to use on average $80 \%$ of their time in day-to-day management activities. Purchased OC is conversely estimated to correspond to $80 \%$ of the turnover of the management consulting services industry.

This methodology has proven very useful in providing first estimates of $O C$ at the macroeconomic level and, more recently, at the industry level, and has contributed to highlighting the importance of such KBC. Following this approach, the INTAN-Invest work based on the EU COINVEST and INNODRIVE projects and on efforts by the US Conference Board - has led to the publication of macro level and industry estimates for the United States and for some European countries. 


\section{A novel task-based approach for the definition and measurement of organisational capital}

Linking the findings of the literature above, it can be concluded that $\mathrm{OC}$ is embodied in a firm's employees - including but not limited to managers - accomplishing a set of tasks related to the long term functioning of a firm, and that labour cost measures of OC may be used to quantify investment in $\mathrm{OC}$ at both the micro and macro levels.

The set of tasks that existing studies suggest to be essential for the generation and accumulation of organisational knowledge and capital relate to:

- developing objectives and strategies;

- organising, planning and prioritising work;

- building teams, matching employees to tasks, and providing training;

- supervising and coordinating activities;

- communicating across and within groups to provide guidance and motivation.

Most of these tasks, traditionally carried out by managers, have been progressively devolved upon non-managerial occupations, due to the decentralisation of authority and the delayering of managerial functions (as underlined in Caroli and Van Reenen, 2001 and von Krogh et al., 2012). Focusing on a task-based approach rather than a priori selecting employees based on their occupational titles, it should thus be possible to more precisely identify that part of the workforce that contributes to the long-term functioning of firms.

\section{Operationalising the task-based approach to measuring human resources related to $\mathrm{OC}$}

The task-based approach proposed in Squicciarini and Le Mouel (2012) is implemented here to estimate investment in OC. In a first step, the tasks that are more likely to correspond to OCrelated activities are identified. In a second step information on the frequency with which workers perform OC-relevant tasks is used to identify those occupations performing OC-related activities to the highest extent. Finally, individual level employment and earnings data are exploited to estimate OC-related employment and investment in organisational capital. This is done at the national and sectoral level, for different firm sizes, and for the private and the public sectors. An important objective of this work is also to assess the extent of cross-country differences in the performance of OC-related tasks and to compare results with those derived from the US-based survey O*NET.

\section{Data: the PIAAC background questionnaire}

This analysis uses data from the Programme for the International Assessment of Adult Competencies (PIAAC) developed by the OECD. Designed in a comparable way to the Programme for International Student Assessment (PISA), this programme consists of a household survey and tests seeking to assess the skill level of the working-age population in the areas of literacy, numeracy and problem-solving. In addition to performing this test, survey respondents also 
provide detailed information on their educational, professional and family background in a complementary questionnaire.

The background questionnaire of PIAAC is the main data source for the present analysis, in particular, the chapter providing internationally comparable information on the tasks performed at work. Mainly carried out in the winter of 2011-2012, the first round of PIAAC data covers average samples of 5,000 adults aged between 16 and 65, in 24 participating OECD member and partner countries. Since their publication, these data have been used to investigate e.g. skill mismatch, using information on skill proficiency, reported skill mismatch and skill use (Pellizzari and Fichen, 2013, and Allen et al. 2013), as well as returns to skills (Hanushek et al. 2015). A further round, using the same tests and questionnaire, was carried out in 9 additional countries and will be published in 2016. Subsequent waves of the Programme are scheduled to add further countries and dimension of testing.

The PIAAC questionnaire contains information on 15 general tasks, such as "sharing information with colleagues" or "working physically", as well as 25 tasks related to skill use in literacy, numeracy and ICT, such as "reading letters, memos or emails" or "calculating prices, costs or budgets". The full list of tasks is provided in Table A1 in the Appendix. While the interpretation might to some extent differ between general tasks and tasks related to skill use, these 40 items are all included in the analysis as they provide additional information and improve the precision of the clustering analysis. They are treated homogenously since the tasks needed to identify OCrelated activities all fall into the first category and results are thus unlikely to be biased.

For each of these 40 items, respondents are asked how often they perform these tasks or use these skills, on a scale of 1 ("Never") to 5 ("Every day"). The task "cooperating and collaborating" is a partial exception to this practice, as the labelling of its scale differs. Its 5 point scale is expressed in terms of proportions of time ("half of the time"...) instead of regularity. However, the information contained in this task is not discarded, as its definition suggests that it does belong to organisational capital and its answers can be easily converted into usable information as they are provided on a 5 point scale, similarly to those of the other tasks. ${ }^{2}$

We restrict our analysis to countries where occupational information is available at the 3 digit level of the ISCO classification. This occupational breakdown is comparable to, albeit slightly less detailed, than that of the O*NET data used in previous analysis focusing on the United States. Given this restriction, our dataset covers 20 countries and 112 occupational categories.

The wealth of worker- and firm-specific information related to age, gender, firm size, nature of the employer (i.e. whether public or private), and status of workers (i.e. employed or selfemployed) contained in PIAAC, in addition to its extensive country coverage, make this data source unique and well suited to the current exercise.

2. Robustness tests show that removing this task from the list does not greatly affect the final selection of OCrelated occupations. 
For every country and occupation, an average answer for each of the 40 tasks is constructed, based on the assumption that workers are homogenous within occupations in terms of the tasks they perform, and that task performance differs across occupations. This index represents the main building block of the analysis.

A first look at this index reveals a feature of the PIAAC questionnaire which is relevant to the present analysis. For occupations at the top of the ISCO classification, corresponding to managers, professionals and associate professionals, the average response over all 40 tasks is persistently above 3 (at least once a month). On the other hand, for occupations listed towards the end of the classification, such as clerical workers, crafts and trades workers and plant and machine operators, the average response is below 2. This implies that they report never performing many of the tasks listed in the questionnaire. In turn this warns about the fact that the daily activities of these occupations are not fully captured in the PIAAC data, while those of managers and professionals seem to be better captured, as can be seen in Figure A1 in the Appendix.

Such a possible shortcoming is irrelevant in the context of the present analysis, as the methodology proposed relies not only on cluster analysis but also on a distribution-based approach, whereby only the top quartile of the distribution is taken into account when identifying OC-related occupation. Also, in so far as OC-related tasks can be identified in the list of tasks detailed in PIAAC, this should not bias our results.

\section{Identifying the tasks related to OC}

The selection of tasks that will serve to discriminate OC-relevant occupations is identified on the basis of a semantic analysis of their description. Three overlapping sets of tasks are thus determined according to the closeness with which they align to the theoretical definition of OC as stated in the previous section. The smallest and core set of tasks encompasses the 3 tasks that explicitly mention organisational activities plus a fourth task relating to teaching and instructing. This list is presented in the third column of Appendix Table A1. It corresponds to a restrictive definition of $\mathrm{OC}$, and ignores the team-building, communication and problem-solving dimensions of organisational activities, which the literature suggests are key components of OC. A broader list of 9 tasks, encompassing these latter activities, is presented in the fourth column of Appendix Table A1. Finally, a more exhaustive list, consisting of 11 tasks, adds a further set of activities that can be associated with communication and instruction and is presented in the final column of Appendix Table A1.

The main analysis in this paper uses the list of 9 tasks, because it captures enough dimensions of OC while remaining parsimonious. The alternative selections of tasks are used for robustness analysis. Table 1 compares the list of 9 OC-related tasks based on the PIAAC data, in the first 2 columns, with the list of 14 OC-related tasks based the O*NET data ${ }^{3}$, in the last 2 columns. Both

3. In the O*NET database, "tasks" refer to occupation-specific activities, while activities comparable across occupations are labelled "work activities". It is the latter, in addition to14 skills and 3 knowledge areas that are used in previous analysis to identify organisational capital. While part of the tasks described in PIAAC are implicitly related to skill use, there is no information concerning knowledge areas. 
datasets capture the concept of organisational capital in its broader sense as they contain information on tasks relating to organisation and planning, but also to team-building, communication and problem solving. Subsequent results on the selection of occupation suggest that the list of 9 tasks performs strongly when it comes to capturing occupations which can be a priori associated with $\mathrm{OC}$, such as managers and supervisors.

Table 1. Selection of OC related tasks, comparison of PIAAC and O*NET databases

\begin{tabular}{|c|c|c|c|}
\hline \multicolumn{2}{|r|}{ PIAAC } & \multicolumn{2}{|r|}{$\mathrm{O}$ *NET } \\
\hline $\begin{array}{l}\text { Task } \\
\text { Code }\end{array}$ & Task Name & $\begin{array}{l}\text { Task } \\
\text { Code }\end{array}$ & Task Name \\
\hline 10 & Cooperating and collaborating & & \\
\hline 11 & Sharing information with co-workers & 412 & Communicating with people inside the organisation \\
\hline $\begin{array}{l}12 \\
20\end{array}$ & $\begin{array}{l}\text { Instructing, training, teaching people } \\
\text { Negotiating with people }\end{array}$ & $\begin{array}{l}422 \\
423 \\
424 \\
425 \\
426\end{array}$ & $\begin{array}{c}\text { Developing and Building Teams } \\
\text { Training and Teaching Others } \\
\text { Guiding, Directing, and Motivating Subordinates } \\
\text { Coaching and Developing Others } \\
\text { Provide Consultation and Advice }\end{array}$ \\
\hline $\begin{array}{l}16 \\
17 \\
18\end{array}$ & $\begin{array}{l}\text { Planning your own activities } \\
\text { Planning the activities of others } \\
\text { Organising your own time }\end{array}$ & $\begin{array}{l}224 \\
225 \\
226 \\
421\end{array}$ & $\begin{array}{c}\text { Developing Objectives and Strategies } \\
\text { Scheduling Work and Activities } \\
\text { Organizing and Prioritizing Work } \\
\text { Coordinating Work and Activities }\end{array}$ \\
\hline $\begin{array}{l}21 \\
22\end{array}$ & $\begin{array}{l}\text { Faced with simple problems } \\
\text { Faced with complex problems }\end{array}$ & 221 & Making Decisions and Solving Problems \\
\hline & & $\begin{array}{l}211 \\
432 \\
433\end{array}$ & $\begin{array}{c}\text { Judging the Qualities of Things, Services, or People } \\
\text { Staffing Organizational Units } \\
\text { Monitoring and Controlling Resources }\end{array}$ \\
\hline
\end{tabular}

Source: Authors' own calculations based on PIAAC data, extracted June 2015, and O*NET data (version 16.0), extracted April 2012

\section{From tasks to occupations: a distribution-based and cluster approach}

The selection of occupations is based on the overlap between two distinct criteria. The first relies on information contained only in the 9 tasks identified above, while the second uses information from the full set of tasks to cluster occupations into groups. The analysis is performed for each country separately, and the results suggest that while there is a core group of occupations (mainly managers) which can be associated with the formation of OC in all countries, differences across countries exist with respect to the other occupations contributing to the generation and accumulation of organisational capital.

\section{A distribution-based approach}

In a first step, a distribution-based approach relying only on the answers to the 9 OC-related tasks identified above is applied. For each occupation in each country, the average and the minimum responses for the 9 OC tasks are calculated. Occupations are then ranked by country 
according to these two measures, and the country-specific cut-off values are defined as the first quartile of occupations that show the highest scores in the answers related to the OC tasks. The cut-off values for the average response range from 3.37 in Germany to 3.99 in Ireland, with an average of 3.62 across the countries considered, which corresponds to performing these tasks between every month (answer 3) and every week (answer 4). The cut-off values for the minimum response range from 1.92 for the Czech Republic to 2.87 for the United Kingdom, with an average of 2.36 across all countries. This corresponds to performing OC-related tasks between less than once a month (answer 2 ) and at least once a month (answer 3 ).

The final selection of occupations is restricted to the overlap between both criteria. An occupation is considered as contributing to the generation of firm-specific $O C$ if workers in that occupation perform all the 9 OC tasks on average almost every week and there is no single task that they perform with a regularity of less than once a month. By definition, the average and the minimum criteria pick up the top quartile of occupations (around 28 occupations). For most countries, the overlap selects one fifth of occupations (around 22 occupations). A notable exception is Korea, where the overlap between the average and the minimum criteria is lower than for the other countries, and only 16 occupations are thus selected.

\section{Clustering analysis}

The distribution-based approach is complemented with country-specific hierarchical clustering analyses of the occupations. This second approach retains the information on all the tasks to allocate occupations into groups and uses the complete linkage (i.e. farthest neighbour) method and the Euclidian measure of distance. The country-specific optimal number of clusters is obtained from the Duda-Hart (1973) criterion. For each cluster, the average response on the 9 OC tasks is then calculated, and the cut-off point defined as the value corresponding to the top quartile. The cut-off values range between 3.39 in Germany and 4.06 in the United Kingdom, with an average of 3.64, and are very similar to the cut-off values that emerge from the distribution-based analysis.

\section{Combining the two for a final selection}

Table 2 presents the final list of OC-related occupations for each country, resulting from the overlap of the selections using the two criteria described above. On average, 19 occupations are identified in each country, with country-specific sets of OC-related occupations that range from 14 occupations in Korea to 24 occupations in Poland. The results confirm the importance of managers in contributing to the formation and accumulation of $\mathrm{OC}$ in firms, as they consistently appear in the selection across countries. In addition, a number of other occupational categories, especially professionals and associate professionals in science and engineering, health, education, and business administration, are identified as being OC-related in many countries.

It is comforting to see that these results are in line with those obtained using the O*NET database (Squicciarini and Le Mouel, 2012), and this suggests that the methodology proposed is robust and results are not sensitive to using information from different sources. Appendix Table A2 presents the detailed comparison, and lists the occupations selected using the O*NET and the 
PIAAC databases for the United States, in the third and fourth columns respectively. The results for the managerial and health occupations are identical, while they differ in the detail for the other professional occupations.

The importance of professional and associate professional occupations, especially in the field of science and engineering, suggests that the creation and accumulation of $\mathrm{OC}$ is likely to overlap with the building up of other knowledge-based assets, such as R\&D, design and computerised information. This is likely to be a source of spillovers with respect to the generation and accumulation of other KBC types, but also of double-counting, when the estimates of the resources devoted to the creation of these different assets uses a labour cost approach à la CHS. Unlike in the O*NET data, the tasks contained in the PIAAC data do not allow for the identification of tasks relating to these other $K B C$ assets, and we cannot bring further evidence on the extent of this overlap.

The comparison of results across countries shows that the main hypothesis concerning the importance of non-managerial occupations for the construction of OC holds, as does the one about the difference in the importance of particular categories across countries. These differences can in part be driven by cross-country heterogeneity in the sectoral composition of the economy, in the organisation of firms and in the understanding of what occupations do and how job titles are consequently classified, in line with Bloom et al (2012). Our estimates of employment and investment at the sectoral level will shed more light on this issue.

\section{Robustness checks using stricter and broader definitions of $O C$}

The sensitivity of the results to the choice of tasks is tested by both restricting and broadening the definition of OC. Firstly, using the narrow definition mentioned above, we keep only 4 tasks (see the fourth column of Table A1 in the Appendix), and replicate the analysis spelled out above. Table 3 summarises the results of this robustness test. In the second column, we show the total number of occupations selected with the 9 tasks, and in the third column the results of using only 4 tasks. The fourth column shows the number of occupations that are the same with both methodologies, and the final column shows the total number of occupations in each country. The overlap between using 9 and 4 tasks is very high in most countries. Korea and the Netherlands are notable exceptions, as there are only 6 and 12 occupations, respectively, that are identified by both criteria. In terms of occupations, there seems to be a bias concerning the ISCO category 230 "Teaching professionals", as many more are selected when using only 4 tasks than when using 9 tasks. This is to be expected as in the restricted definition of OC, the task "instructing and teaching others" has a more important weight than in the broader definition. This confirms that the broader definition of $O C$ is more appropriate, as it is better able to discriminate between occupations.

Secondly, we broaden the definition of OC, to include 11 tasks: we drop task 10 "Cooperating and collaborating", and add three communication tasks (see the fifth column of Table A1 in the Appendix). The results are summarised in Table 4, and show very little difference with those obtained with the main analysis. Looking at the occupations, there seems to be no occupational category that is favoured by one or the other criteria. This suggests that including the 
communication related tasks does not add substantial information to the analysis. Hence, since the inclusion of such additional tasks, while justifiable on the basis of the definition of OC, does not add anything to the analysis, it is preferable to remain parsimonious and limit the number of tasks used for the analysis to 9. 
Table 2. Selection of OC-related occupations by country

\begin{tabular}{|c|c|c|c|c|c|c|c|c|c|c|c|c|c|c|c|c|c|c|c|c|c|c|}
\hline ISCO & ISCO Title & AUT & BEL & CAN & CZE & DEU & DNK & ESP & EST & FRA & GBR & IRL & ITA & JPN & KOR & NLD & NOR & POL & SVK & SWE & USA & TOTAL \\
\hline 1 & Managers & & & & & & & & & & & & & & & & & & & & & \\
\hline 110 & Chief executives and legislators & $\sqrt{ }$ & $\sqrt{ }$ & $\sqrt{ }$ & $\sqrt{ }$ & $\sqrt{ }$ & $\sqrt{ }$ & $\sqrt{ }$ & $\sqrt{ }$ & & & $\sqrt{ }$ & $\sqrt{ }$ & $\sqrt{ }$ & & $\sqrt{ }$ & $\sqrt{ }$ & $\sqrt{ }$ & $\sqrt{ }$ & $\sqrt{ }$ & $\sqrt{ }$ & 17 \\
\hline 121 & $\begin{array}{l}\text { Business services and } \\
\text { administration }\end{array}$ & $\sqrt{ }$ & $\sqrt{ }$ & $\sqrt{ }$ & $\sqrt{ }$ & $\sqrt{ }$ & $\sqrt{ }$ & $\sqrt{ }$ & $\sqrt{ }$ & $\sqrt{ }$ & $\sqrt{ }$ & $\sqrt{ }$ & $\sqrt{ }$ & $\sqrt{ }$ & $\sqrt{ }$ & $\sqrt{ }$ & $\sqrt{ }$ & $\sqrt{ }$ & $\sqrt{ }$ & $\sqrt{ }$ & $\sqrt{ }$ & 20 \\
\hline 122 & Sales, marketing and development & $\sqrt{ }$ & $\sqrt{ }$ & $\sqrt{ }$ & $\sqrt{ }$ & $\sqrt{ }$ & $\sqrt{ }$ & $\sqrt{ }$ & $\sqrt{ }$ & $\sqrt{ }$ & $\sqrt{ }$ & $\sqrt{ }$ & $\sqrt{ }$ & $\sqrt{ }$ & $\sqrt{ }$ & $\sqrt{ }$ & $\sqrt{ }$ & $\sqrt{ }$ & $\sqrt{ }$ & $\sqrt{ }$ & $\sqrt{ }$ & 20 \\
\hline 131 & Production managers in agriculture & & & & $\sqrt{ }$ & & $\sqrt{ }$ & & $\sqrt{ }$ & $\sqrt{ }$ & $\sqrt{ }$ & & & & & & & $\sqrt{ }$ & & & $\sqrt{ }$ & 7 \\
\hline 132 & $\begin{array}{l}\text { Manufacturing, mining, construction, } \\
\text { and distribution }\end{array}$ & $\sqrt{ }$ & $\sqrt{ }$ & $\sqrt{ }$ & $\sqrt{ }$ & $\sqrt{ }$ & $\sqrt{ }$ & $\sqrt{ }$ & $\sqrt{ }$ & $\sqrt{ }$ & $\sqrt{ }$ & $\sqrt{ }$ & $\sqrt{ }$ & $\sqrt{ }$ & $\sqrt{ }$ & $\sqrt{ }$ & $\sqrt{ }$ & $\sqrt{ }$ & $\sqrt{ }$ & $\sqrt{ }$ & $\sqrt{ }$ & 20 \\
\hline 133 & ICT services & $\sqrt{ }$ & $\sqrt{ }$ & $\sqrt{ }$ & $\sqrt{ }$ & $\sqrt{ }$ & $\sqrt{ }$ & $\sqrt{ }$ & $\sqrt{ }$ & $\sqrt{ }$ & & $\sqrt{ }$ & & $\sqrt{ }$ & & $\sqrt{ }$ & $\sqrt{ }$ & $\sqrt{ }$ & $\sqrt{ }$ & $\sqrt{ }$ & $\sqrt{ }$ & 17 \\
\hline 134 & Professional services & $\sqrt{ }$ & $\sqrt{ }$ & $\sqrt{ }$ & $\sqrt{ }$ & $\sqrt{ }$ & $\sqrt{ }$ & $\sqrt{ }$ & $\sqrt{ }$ & $\sqrt{ }$ & $\sqrt{ }$ & $\sqrt{ }$ & $\sqrt{ }$ & $\sqrt{ }$ & $\sqrt{ }$ & $\sqrt{ }$ & $\sqrt{ }$ & $\sqrt{ }$ & $\sqrt{ }$ & $\sqrt{ }$ & $\sqrt{ }$ & 20 \\
\hline 141 & Hotel and restaurant & $\sqrt{ }$ & & $\sqrt{ }$ & & $\sqrt{ }$ & $\sqrt{ }$ & & $\sqrt{ }$ & $\sqrt{ }$ & & & & $\sqrt{ }$ & & & & $\sqrt{ }$ & & $\sqrt{ }$ & $\sqrt{ }$ & 10 \\
\hline 142 & Retail and wholesale trade & $\sqrt{ }$ & $\sqrt{ }$ & $\sqrt{ }$ & $\sqrt{ }$ & $\sqrt{ }$ & $\sqrt{ }$ & $\sqrt{ }$ & $\sqrt{ }$ & $\sqrt{ }$ & $\sqrt{ }$ & & & $\sqrt{ }$ & $\sqrt{ }$ & $\sqrt{ }$ & $\sqrt{ }$ & $\sqrt{ }$ & $\sqrt{ }$ & $\sqrt{ }$ & $\sqrt{ }$ & 18 \\
\hline 143 & Other services & $\sqrt{ }$ & $\sqrt{ }$ & $\sqrt{ }$ & $\sqrt{ }$ & $\sqrt{ }$ & $\sqrt{ }$ & $\sqrt{ }$ & $\sqrt{ }$ & $\sqrt{ }$ & $\sqrt{ }$ & $\sqrt{ }$ & $\sqrt{ }$ & $\sqrt{ }$ & & $\sqrt{ }$ & & $\sqrt{ }$ & $\sqrt{ }$ & & $\sqrt{ }$ & 17 \\
\hline 2 & Professionals & & & & & & & & & & & & & & & & & & & & & \\
\hline 211 & Physical and earth science & $\sqrt{ }$ & & $\sqrt{ }$ & & & & & & & & & $\sqrt{ }$ & & $\sqrt{ }$ & & $\sqrt{ }$ & $\sqrt{ }$ & & & & 6 \\
\hline 212 & $\begin{array}{l}\text { Mathematicians, actuaries and } \\
\text { statisticians }\end{array}$ & & $\sqrt{ }$ & & $\sqrt{ }$ & & & & & & & & & & & & & & & & & 2 \\
\hline 213 & Life sciences & $\sqrt{ }$ & & & & $\sqrt{ }$ & & & & & & & & & & & & & & & & 2 \\
\hline 214 & Engineers & $\sqrt{ }$ & $\sqrt{ }$ & $\sqrt{ }$ & & $\sqrt{ }$ & $\sqrt{ }$ & $\sqrt{ }$ & $\sqrt{ }$ & $\sqrt{ }$ & $\sqrt{ }$ & & $\sqrt{ }$ & & $\sqrt{ }$ & $\sqrt{ }$ & $\sqrt{ }$ & $\sqrt{ }$ & & & & 14 \\
\hline 215 & Electrotechnology engineers & $\sqrt{ }$ & $\sqrt{ }$ & $\sqrt{ }$ & & & & & $\sqrt{ }$ & & & & $\sqrt{ }$ & & $\sqrt{ }$ & $\sqrt{ }$ & & $\sqrt{ }$ & & & & 8 \\
\hline 216 & Architects, planners and designers & & & & $\sqrt{ }$ & & & & $\sqrt{ }$ & & & & & & & & & & & & & 2 \\
\hline 220 & Health professionals, except doctors & & & $\sqrt{ }$ & & & & $\sqrt{ }$ & & $\sqrt{ }$ & $\sqrt{ }$ & & & & & & $\sqrt{ }$ & & & & $\sqrt{ }$ & 6 \\
\hline 221 & Medical doctors & $\sqrt{ }$ & $\sqrt{ }$ & $\sqrt{ }$ & $\sqrt{ }$ & $\sqrt{ }$ & $\sqrt{ }$ & & $\sqrt{ }$ & & $\sqrt{ }$ & $\sqrt{ }$ & $\sqrt{ }$ & $\sqrt{ }$ & $\sqrt{ }$ & $\sqrt{ }$ & $\sqrt{ }$ & $\sqrt{ }$ & & $\sqrt{ }$ & $\sqrt{ }$ & 17 \\
\hline 231 & Higher education teachers & $\sqrt{ }$ & $\sqrt{ }$ & & & $\sqrt{ }$ & $\sqrt{ }$ & $\sqrt{ }$ & & $\sqrt{ }$ & $\sqrt{ }$ & & & $\sqrt{ }$ & & $\sqrt{ }$ & & & $\sqrt{ }$ & & & 10 \\
\hline 232 & Vocational education teachers & & & $\sqrt{ }$ & & $\sqrt{ }$ & $\sqrt{ }$ & & & $\sqrt{ }$ & & & $\sqrt{ }$ & & & & & & $\sqrt{ }$ & & $\sqrt{ }$ & 7 \\
\hline 233 & Secondary education teachers & $\sqrt{ }$ & & $\sqrt{ }$ & $\sqrt{ }$ & & & $\sqrt{ }$ & & $\sqrt{ }$ & $\sqrt{ }$ & $\sqrt{ }$ & & $\sqrt{ }$ & & & & $\sqrt{ }$ & $\sqrt{ }$ & & $\sqrt{ }$ & 11 \\
\hline 234 & Pre- and primary school teachers & & & & & $\sqrt{ }$ & & & $\sqrt{ }$ & $\sqrt{ }$ & $\sqrt{ }$ & $\sqrt{ }$ & & & & & $\sqrt{ }$ & $\sqrt{ }$ & $\sqrt{ }$ & $\sqrt{ }$ & $\sqrt{ }$ & 10 \\
\hline 235 & Other teaching professionals & & & $\sqrt{ }$ & & $\sqrt{ }$ & & & & & $\sqrt{ }$ & & & & & & & & $\sqrt{ }$ & $\sqrt{ }$ & & 5 \\
\hline 241 & Finance & $\sqrt{ }$ & & & $\sqrt{ }$ & & & $\sqrt{ }$ & & & & & $\sqrt{ }$ & & & $\sqrt{ }$ & $\sqrt{ }$ & & & & & 6 \\
\hline 242 & Administration & $\sqrt{ }$ & $\sqrt{ }$ & $\sqrt{ }$ & $\sqrt{ }$ & $\sqrt{ }$ & $\sqrt{ }$ & $\sqrt{ }$ & & $\sqrt{ }$ & & $\sqrt{ }$ & $\sqrt{ }$ & $\sqrt{ }$ & & $\sqrt{ }$ & & $\sqrt{ }$ & & & & 13 \\
\hline 243 & Sales, marketing and PR & $\sqrt{ }$ & & & $\sqrt{ }$ & $\sqrt{ }$ & $\sqrt{ }$ & & $\sqrt{ }$ & & & $\sqrt{ }$ & & & & & $\sqrt{ }$ & $\sqrt{ }$ & & & & 8 \\
\hline 251 & $\begin{array}{l}\text { Software and applications } \\
\text { developers and analysts }\end{array}$ & & & & & & & & & & & $\sqrt{ }$ & $\sqrt{ }$ & & $\sqrt{ }$ & $\sqrt{ }$ & & & & & & 4 \\
\hline 252 & Database and network & & & & $\sqrt{ }$ & & $\sqrt{ }$ & & & & & $\sqrt{ }$ & & & & $\sqrt{ }$ & & & $\sqrt{ }$ & & & 5 \\
\hline 261 & Legal professionals & & & $\sqrt{ }$ & & & & & & & $\sqrt{ }$ & $\sqrt{ }$ & & $\sqrt{ }$ & & & & $\sqrt{ }$ & $\sqrt{ }$ & $\sqrt{ }$ & $\sqrt{ }$ & 8 \\
\hline 262 & Librarians, archivists and curators & & & & & & & & & & & $\sqrt{ }$ & & & & & & & & & & 1 \\
\hline
\end{tabular}




\begin{tabular}{|c|c|c|c|c|c|c|c|c|c|c|c|c|c|c|c|c|c|c|c|c|c|c|}
\hline 263 & Social and religious professionals & & & $\sqrt{ }$ & & $\sqrt{ }$ & & $\sqrt{ }$ & & & $\sqrt{ }$ & & & & $\sqrt{ }$ & & & & & & $\sqrt{ }$ & 6 \\
\hline 3 & $\begin{array}{l}\text { Technicians and associate } \\
\text { professionals }\end{array}$ & & & & & & & & & & & & & & & & & & & & & \\
\hline 312 & $\begin{array}{l}\text { Mining, manufacturing and } \\
\text { construction supervisors }\end{array}$ & $\sqrt{ }$ & $\sqrt{ }$ & $\sqrt{ }$ & $\sqrt{ }$ & $\sqrt{ }$ & $\sqrt{ }$ & & $\sqrt{ }$ & & & & $\sqrt{ }$ & $\sqrt{ }$ & & $\sqrt{ }$ & & $\sqrt{ }$ & $\sqrt{ }$ & & $\sqrt{ }$ & 13 \\
\hline 313 & Process control technicians & & & & & $\sqrt{ }$ & & & & & & & & & & & & & $\sqrt{ }$ & & & 2 \\
\hline 314 & Life science & & & & & & & & & & & & & & & & & $\sqrt{ }$ & $\sqrt{ }$ & $\sqrt{ }$ & & 3 \\
\hline 315 & Ship and aircraft controllers & $\sqrt{ }$ & & & & & & & $\sqrt{ }$ & & & & $\sqrt{ }$ & & & & & $\sqrt{ }$ & & & & 4 \\
\hline 322 & Nursing and midwifery & & & $\sqrt{ }$ & & & & & & $\sqrt{ }$ & $\sqrt{ }$ & & & & & & $\sqrt{ }$ & & & & $\sqrt{ }$ & 5 \\
\hline 331 & Finance and mathematical sciences & & & & & & & & & & & $\sqrt{ }$ & & & $\sqrt{ }$ & & & & & & & 2 \\
\hline 332 & Sales agents and brokers & & & & $\sqrt{ }$ & & & & & & & & $\sqrt{ }$ & $\sqrt{ }$ & & $\sqrt{ }$ & & & & & & 4 \\
\hline 333 & Business services agents & $\sqrt{ }$ & & & & & & & $\sqrt{ }$ & & & $\sqrt{ }$ & $\sqrt{ }$ & & & $\sqrt{ }$ & $\sqrt{ }$ & $\sqrt{ }$ & & & & 7 \\
\hline 334 & Administrative secretaries & & & & & & & $\sqrt{ }$ & & $\sqrt{ }$ & $\sqrt{ }$ & & & $\sqrt{ }$ & & & & & & & & 4 \\
\hline 341 & Legal, social and religious & & $\sqrt{ }$ & & & & & & $\sqrt{ }$ & & $\sqrt{ }$ & & & & & & & & & & & 3 \\
\hline 342 & Sports and fitness workers & & & & & & & & $\sqrt{ }$ & & & & & & & & & & & & & 1 \\
\hline 351 & $\begin{array}{l}\text { ICT operations and user support } \\
\text { technicians }\end{array}$ & & $\sqrt{ }$ & & & & & & & & & & & & & & & & & & & 1 \\
\hline 352 & $\begin{array}{l}\text { Telecommunications and } \\
\text { broadcasting technicians }\end{array}$ & & & & & & & $\sqrt{ }$ & & & & & & & & & & $\sqrt{ }$ & $\sqrt{ }$ & & & 3 \\
\hline 4 & Clerical support workers & & & & & & & & & & & & & & & & & & & & & \\
\hline 421 & Tellers, money collectors and clerks & $\sqrt{ }$ & & & & & & & & & & & & & & & & & & & & 1 \\
\hline 441 & Other clerical support workers & & & & & & & & & & & & & & $\sqrt{ }$ & & & & & & & 1 \\
\hline 5 & Services and sales workers & & & & & & & & & & & & & & & & & & & & & \\
\hline 516 & Other personal services workers & & & & & & & & & & & & $\sqrt{ }$ & & & & & & & & & 1 \\
\hline 531 & $\begin{array}{l}\text { Child care workers and teachers' } \\
\text { aides }\end{array}$ & & & & & & & & & & & & & & & & & & $\sqrt{ }$ & & & 1 \\
\hline 7 & Craft and trades workers & & & & & & & & & & & & & & & & & & & & & \\
\hline 732 & Printing trades workers & & & & & & & & & & & & $\sqrt{ }$ & & & & & & & & & 1 \\
\hline 741 & $\begin{array}{l}\text { Electrical equipment installers and } \\
\text { repairers }\end{array}$ & & & & & & & & & & & & & & & & $\sqrt{ }$ & & & & & 1 \\
\hline 753 & Garment and related trades workers & & & & & & & & & & & & & & & & & & & $\sqrt{ }$ & & 1 \\
\hline 754 & Other craft and related workers & & & & & & & & & & & & & & & & & & & $\sqrt{ }$ & & 1 \\
\hline 8 & Plant and machine operators & & & & & & & & & & & & & & & & & & & & & \\
\hline 811 & Mining and mineral processing & & & & & & & & & & & & & & & & & & & $\sqrt{ }$ & & 1 \\
\hline 817 & Wood processing and papermaking & & & & & & & & & & & & & & $\sqrt{ }$ & & & & & & & 1 \\
\hline \multirow[t]{2}{*}{835} & $\begin{array}{l}\text { Ships' deck crews and related } \\
\text { workers }\end{array}$ & & & & & & & & & & & $\sqrt{ }$ & & & & & & & & & & 1 \\
\hline & TOTAL & 23 & 17 & 22 & 19 & 21 & 18 & 17 & 21 & 18 & 19 & 18 & 20 & 17 & 14 & 19 & 17 & 24 & 20 & 16 & 19 & \\
\hline
\end{tabular}

Source: Authors' calculations based on the PIAAC database, extracted June 2015. 
Table 3. Robustness analysis using 4 OC-tasks

\begin{tabular}{|l|cccc|}
\hline Country & $\begin{array}{c}\text { Selection using 9 } \\
\text { tasks }\end{array}$ & $\begin{array}{c}\text { Selection using 4 } \\
\text { tasks }\end{array}$ & Overlap & $\begin{array}{c}\text { Total number of } \\
\text { occupations }\end{array}$ \\
\hline AUT & 23 & 19 & 17 & 110 \\
BEL & 17 & 19 & 14 & 109 \\
CAN & 22 & 22 & 18 & 112 \\
CZE & 19 & 23 & 18 & 110 \\
DEU & 19 & 21 & 19 & 101 \\
DNK & 18 & 20 & 15 & 112 \\
ESP & 17 & 19 & 14 & 111 \\
EST & 21 & 24 & 20 & 112 \\
FRA & 18 & 19 & 16 & 108 \\
GBR & 19 & 21 & 17 & 101 \\
IRL & 18 & 20 & 14 & 106 \\
ITA & 20 & 18 & 15 & 112 \\
JPN & 17 & 18 & 15 & 111 \\
KOR & 14 & 15 & 6 & 109 \\
NLD & 19 & 21 & 12 & 109 \\
NOR & 17 & 21 & 14 & 101 \\
POL & 24 & 24 & 20 & 111 \\
SVK & 20 & 21 & 20 & 111 \\
SWE & 16 & 20 & 15 & 108 \\
USA & 19 & 21 & 17 & 110 \\
\hline
\end{tabular}

Source: Authors' calculations based on the PIAAC database, extracted June 2015.

Table 4. Robustness analysis using 11 OC-tasks

\begin{tabular}{|c|cccc|}
\hline Country & $\begin{array}{c}\text { Selection using 9 } \\
\text { tasks }\end{array}$ & $\begin{array}{c}\text { Selection using } \\
\text { 11 tasks }\end{array}$ & Overlap & $\begin{array}{c}\text { Total number of } \\
\text { occupations }\end{array}$ \\
\hline AUT & 23 & 24 & 22 & 110 \\
BEL & 17 & 16 & 14 & 109 \\
CAN & 22 & 21 & 21 & 112 \\
CZE & 19 & 22 & 19 & 110 \\
DEU & 19 & 20 & 19 & 101 \\
DNK & 18 & 15 & 12 & 112 \\
ESP & 17 & 18 & 17 & 111 \\
EST & 21 & 25 & 19 & 112 \\
FRA & 18 & 16 & 12 & 108 \\
GBR & 19 & 19 & 18 & 101 \\
IRL & 18 & 19 & 17 & 106 \\
ITA & 20 & 20 & 20 & 112 \\
JPN & 17 & 17 & 17 & 111 \\
KOR & 14 & 20 & 12 & 109 \\
NLD & 19 & 21 & 18 & 109 \\
NOR & 17 & 18 & 14 & 101 \\
POL & 24 & 20 & 16 & 111 \\
SVK & 20 & 19 & 17 & 111 \\
SWE & 16 & 14 & 10 & 110 \\
USA & 19 & 20 & 19 & \\
\hline
\end{tabular}

Source: Authors' calculations based on the PIAAC database, extracted June 2015. 


\section{Quantifying the human resources contributing to OC formation}

Given the identification of those occupations that contribute to the generation and accumulation of organisational knowledge, this study quantifies the importance of this asset in the economy. Using the employment and earnings information provided at the individual level in the PIAAC survey, survey respondents are classified according to whether they are employed in an OC-related occupation or not. Aggregating such figures across these individuals yields OC employment and investment for each of the 20 countries. To this end, survey weights are recalibrated to be representative of the aggregate and industry employment structure, according to external labour force surveys and following a methodology described in Squicciarini et al. (2015). Given these adjusted sample weights, total employment, including both employees and the self-employed, is calculated for each country. Employment by industry, firm size and in the public and private sectors is also obtained by aggregating across the relevant survey respondents according to the appropriate dimension.

Investment in OC is then calculated applying the methodology of CHS whereby investment in OC consists of $20 \%$ of the wages paid to the relevant occupations. For comparability, investment figures are presented as a ratio of value-added, obtained from the OECD STAN database. The assumption that $20 \%$ of wages represent investment in OC is derived from the management literature where it is suggested that managers spend around one fifth of their time of activities that affect the long-term functioning of firms (CHS, 2009). This assumption, which is not tested in the context of the present paper due to the lack of relevant information, would deserve further investigation in the future. The breakdown of investment into the various categories is obtained in a similar fashion.

Figure 1 plots the proportion of total OC-related and of managerial employment in the economy for the year 2012. The latter figures reflect the results that would be obtained by following the CHS methodology, which looks exclusively at managerial occupations. While the share of managers in total employment ranges from $2 \%$ in Korea to $10 \%$ in the United Kingdom, the United States and Canada, the share of all OC-related employees ranges from 9.5\% in Denmark to $26 \%$ in the United Kingdom. Across countries, the share of managers in total employment averages $6.5 \%$ while the share of non-managerial OC occupations averages $10 \%$. The proposed measure of OC-related employment is on average 2.7 times higher than the number of managerial workers only. These figures suggest that in all countries, non-managerial workers account for the majority of OC related activities and that overlooking them entails substantially underestimating investment in organisational capital.

Figure 2 depicts investment in OC, as a share of total value-added, for the year 2012, again separating out the fraction attributable to managerial occupations from that attributable to nonmanagerial occupations. Investment in $\mathrm{OC}$ as a share of value-added attributable to managerial occupations ranges from $0.4 \%$ in Korea to $1.8 \%$ in the United Kingdom, while total investment in $\mathrm{OC}$ as a share of value-added ranges from $1.4 \%$ in the Czech Republic to $3.7 \%$ in the United Kingdom. Across countries, these values are $1 \%$ and $2.2 \%$ respectively. Hence, including nonmanagerial occupations results in estimates of investment in OC that are on average 2.3 times higher than those obtained considering only managerial occupations. 
Figure 3 shows the breakdown between the manufacturing sector (ISIC Revision 3, sectors 15 to 37) and the services sector (ISIC Revision 3, sectors 50 to 93) separately. For many countries, the share of managers in manufacturing and in services is similar, while the share of non-managerial OC occupations differs greatly. With the exception of Japan, Germany, Belgium and Italy, investment in $\mathrm{OC}$ is higher in services than in manufacturing. This is in line with what could be expected given the industrial structure of these countries.

Figure 1. OC-related workers, 2012

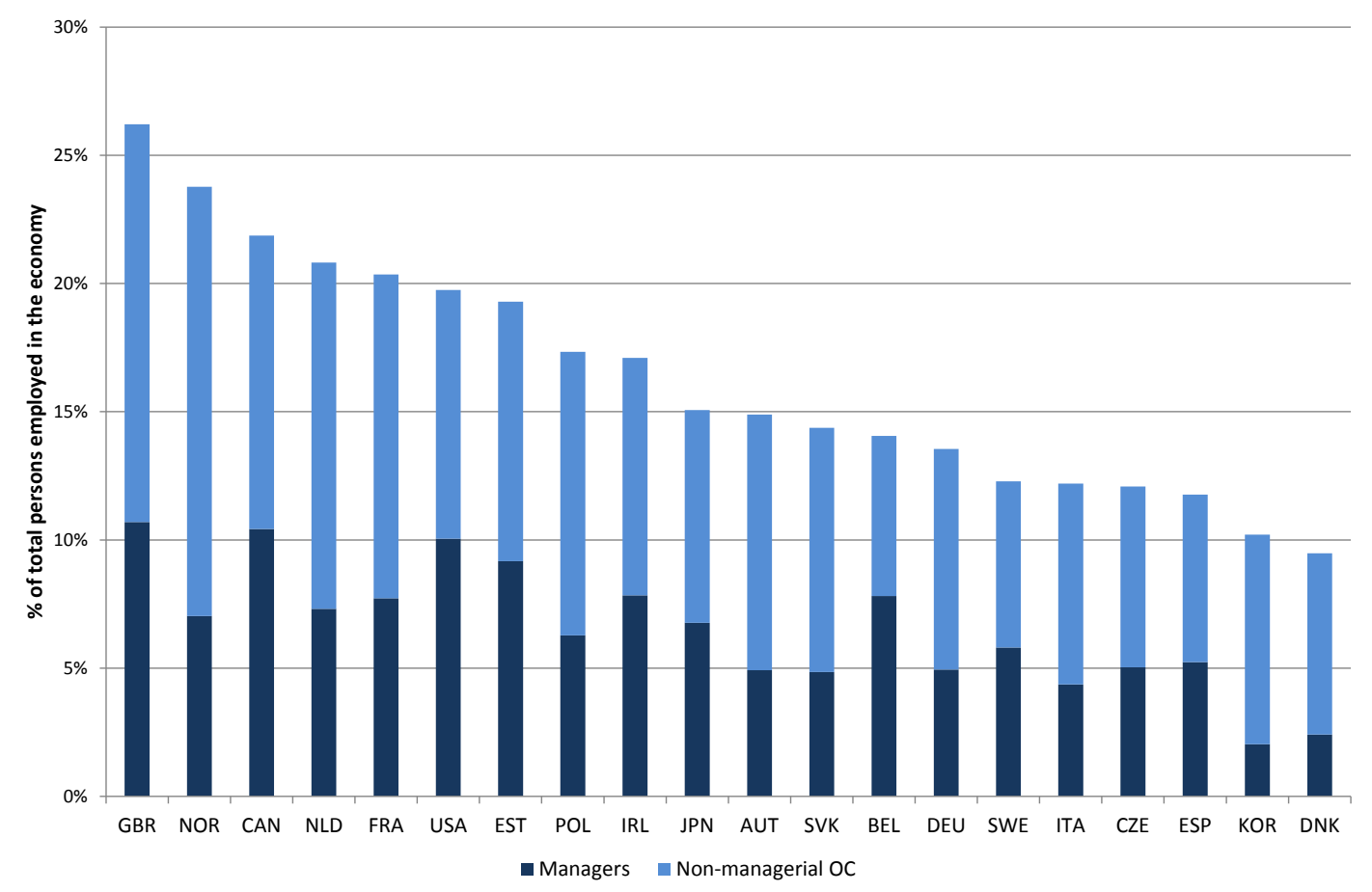

Source: Authors' own calculations based on publicly available PIAAC data, extracted June 2015. 
Figure 2. Investment in OC, as a percentage of total value-added in the economy, 2012

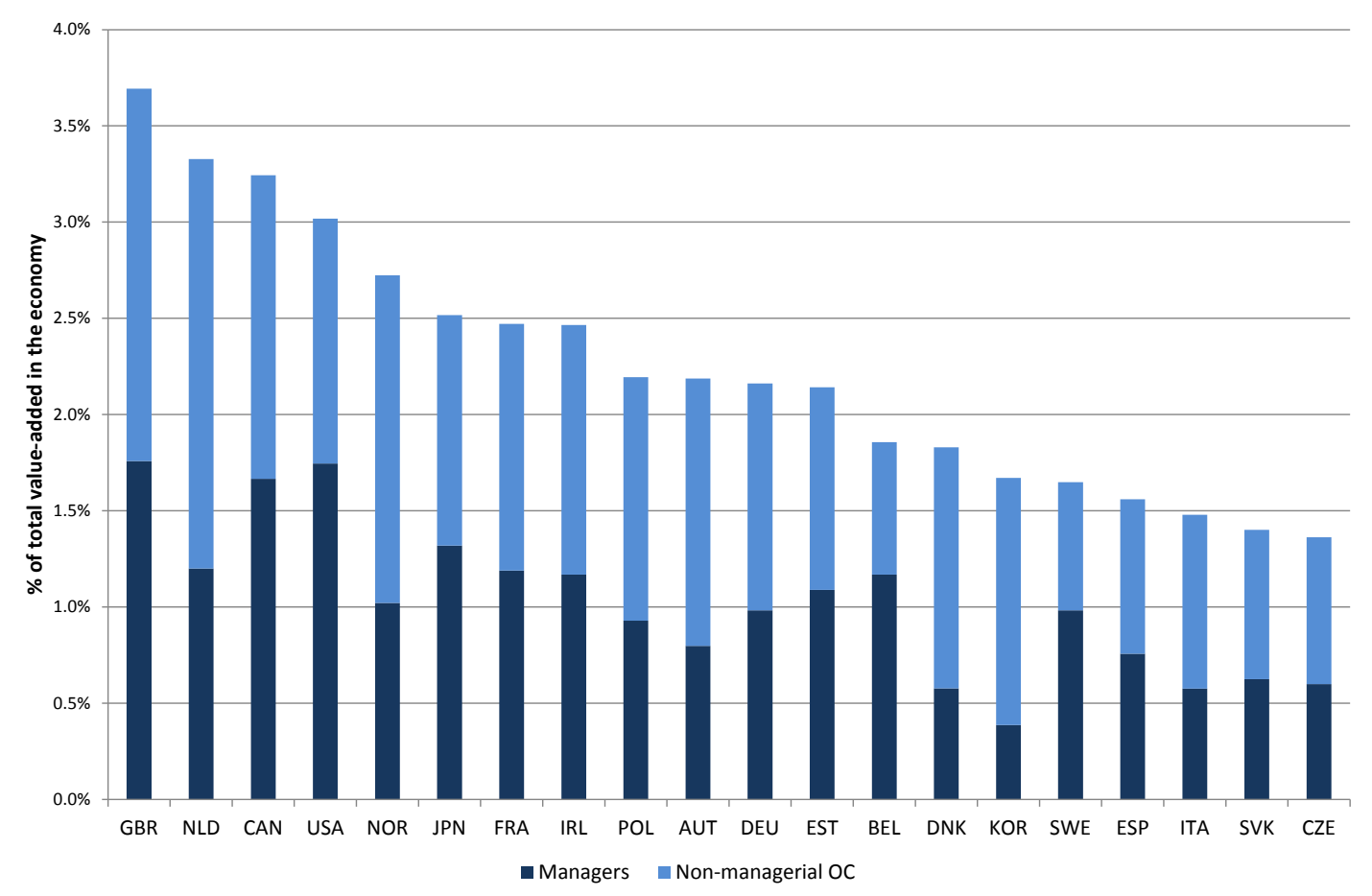

Source: Authors' own calculations based on publicly available PIAAC data and OECD STAN database, extracted June 2015. 
Figure 3. OC investment in manufacturing and services, 2012

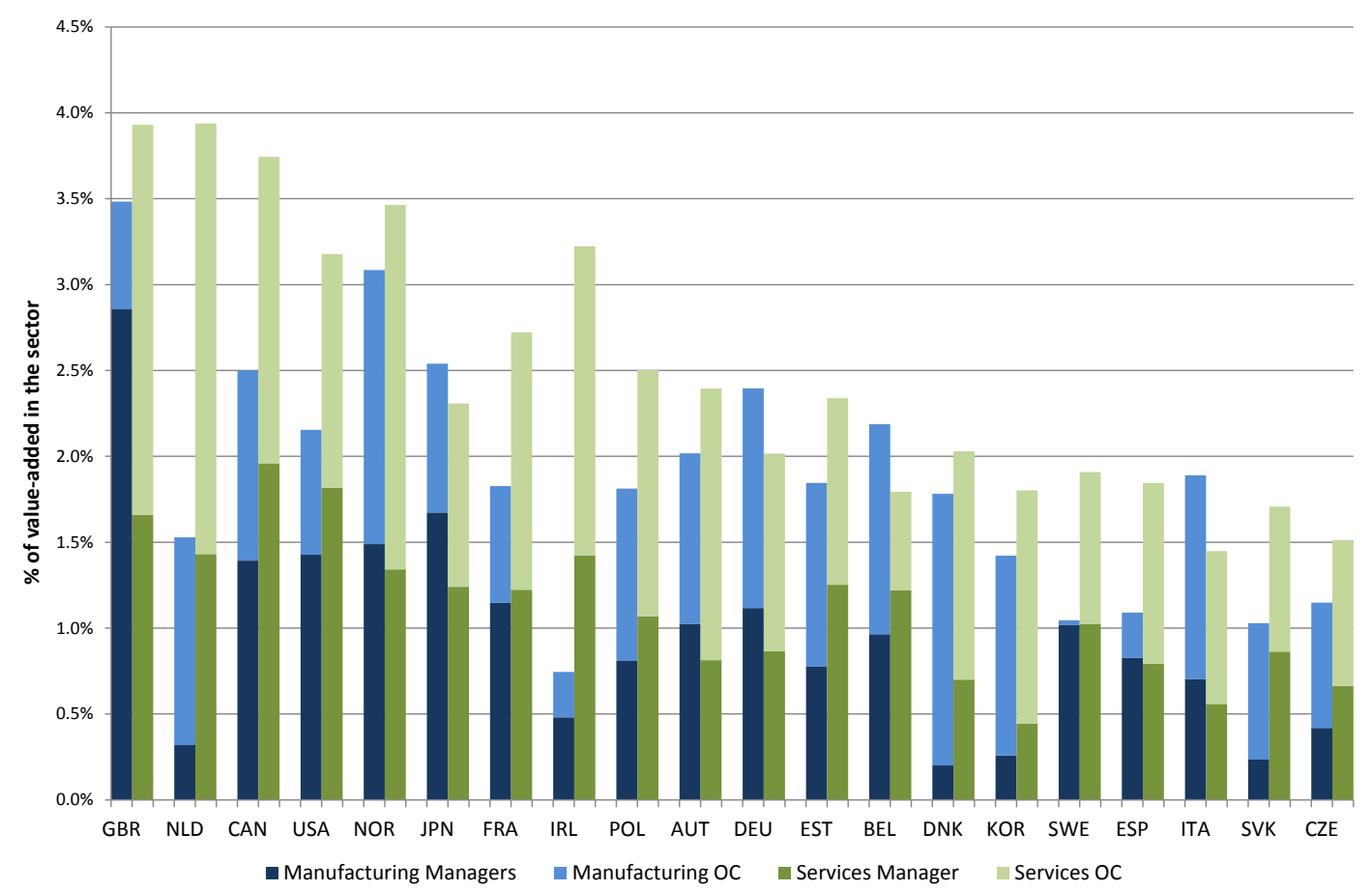

Source: Authors' own calculations based on publicly available PIAAC data and OECD STAN database, extracted June 2015.

Legend: "Manufacturing $O^{\circ}$ " and "Services $O C$ " refer to those occupations contributing to the generation of Organisational Capital other than managers, in manufacturing and services, respectively. Countries are sorted in descending order of OC investment intensity for the total economy, as in Figure 2.

Figure 4 shows the breakdown of OC investment for small ( 1 to 50 employees), medium (51 to 250 employees) and large (more than 251 employees) firms. In the services sector, small firms account for on average half of OC investment in that sector, while in manufacturing, $45 \%$ of OC investment comes from large firms.

Figure 5 shows the role of the self-employed in OC. The dark blue line shows their share in OC employment, and the light blue line in OC investment. The black diamonds represent the benchmark share of self-employed in total employment. In seven of the twenty countries, the share of the self-employed in OC employment is smaller than their share in total employment. Norway is the country where the self-employed represent the smallest share of total employment and investment in OC, at only 7\%. While Korea has the highest share of selfemployed in total employment $(24 \%)$, it is in Italy that they drive the largest share of OC investment (34\%). 
Figure 4. OC investment by firm size, 2012

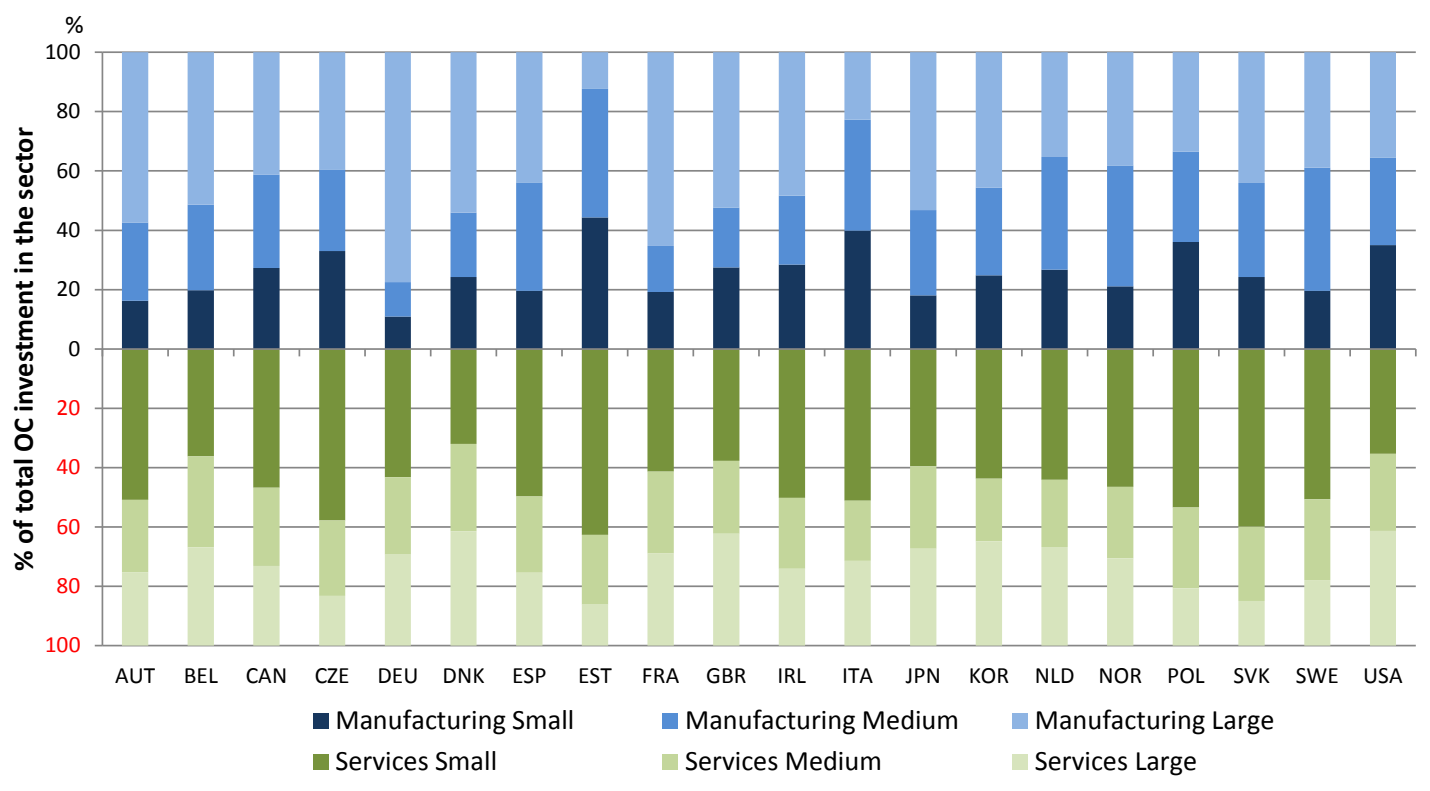

Source: OECD (2015).

Legend: "Manufacturing $O O^{\prime}$ " and "Services $O C$ " refer to those occupations contributing to the generation of Organisational Capital other than managers, in manufacturing and services, respectively. Countries are sorted in descending order of OC investment intensity for the total economy, as in Figure 2. 
Figure 5. Share of the self-employed in OC employment, OC investment and total employment, 2012

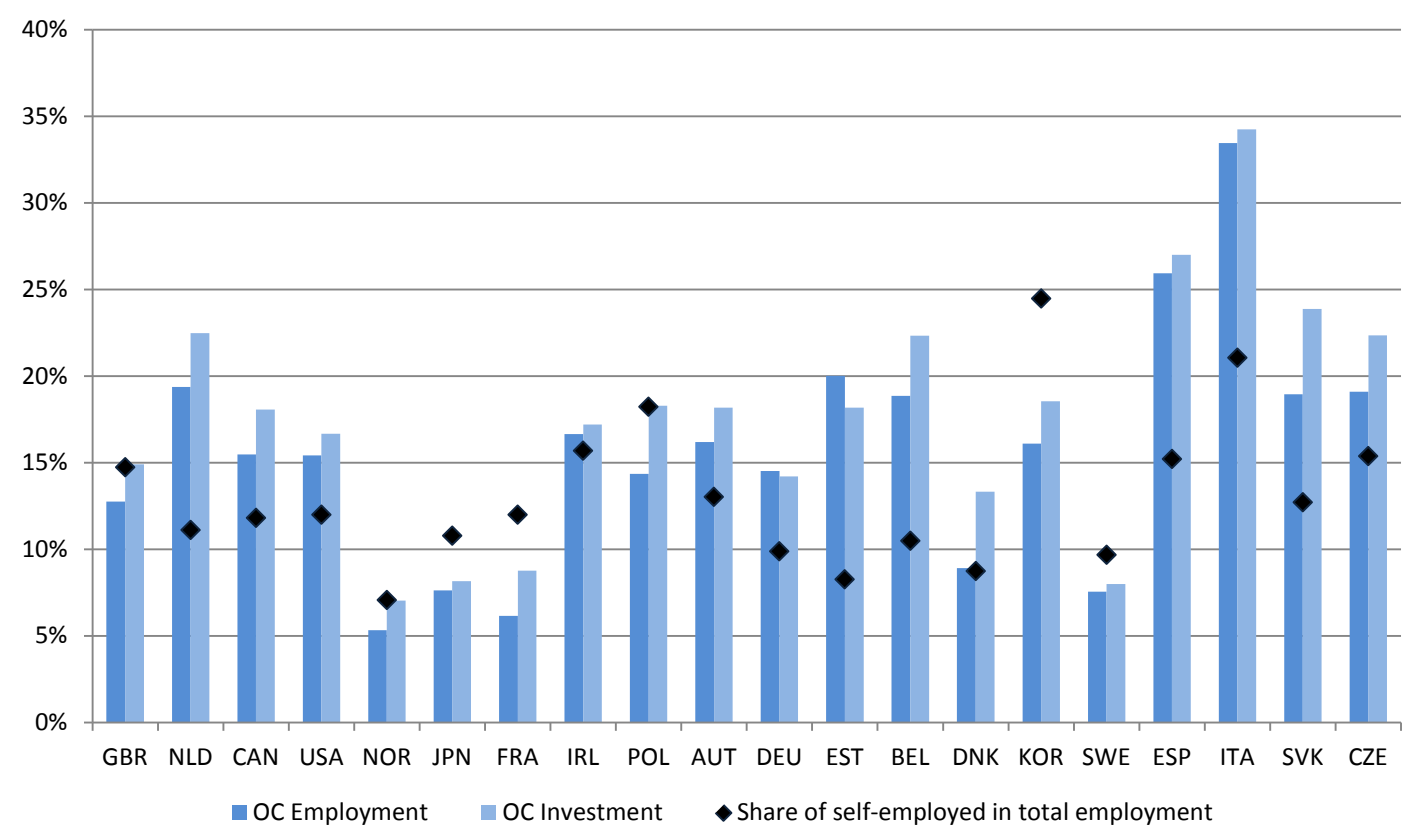

Source: Authors' own calculations based on publicly available PIAAC data and OECD STAN database, extracted June 2015.

Legend: Countries are sorted in descending order of OC investment intensity for the total economy, as in Figure 2. 
Figure 6 offers a more detailed view of the industry level and shows the distribution of OC investment across countries for each sector. Median investment in OC ranges from $0.5 \%$ of value-added for real estate activities, to $6 \%$ in education. Some sectors display very high dispersion across countries. This is true especially in renting of machinery; coke, refined petroleum products and nuclear fuel; and electrical machinery and apparatus, where the ratio of the top $10 \%$ of OC investors to the bottom $10 \%$ of OC investors is higher than 15 . The sectors with the smallest dispersion, where this ratio is smaller than 3 , are wholesale and retail trade, and R\&D and business activities.

Figure 6.0C investment by industry, 2012

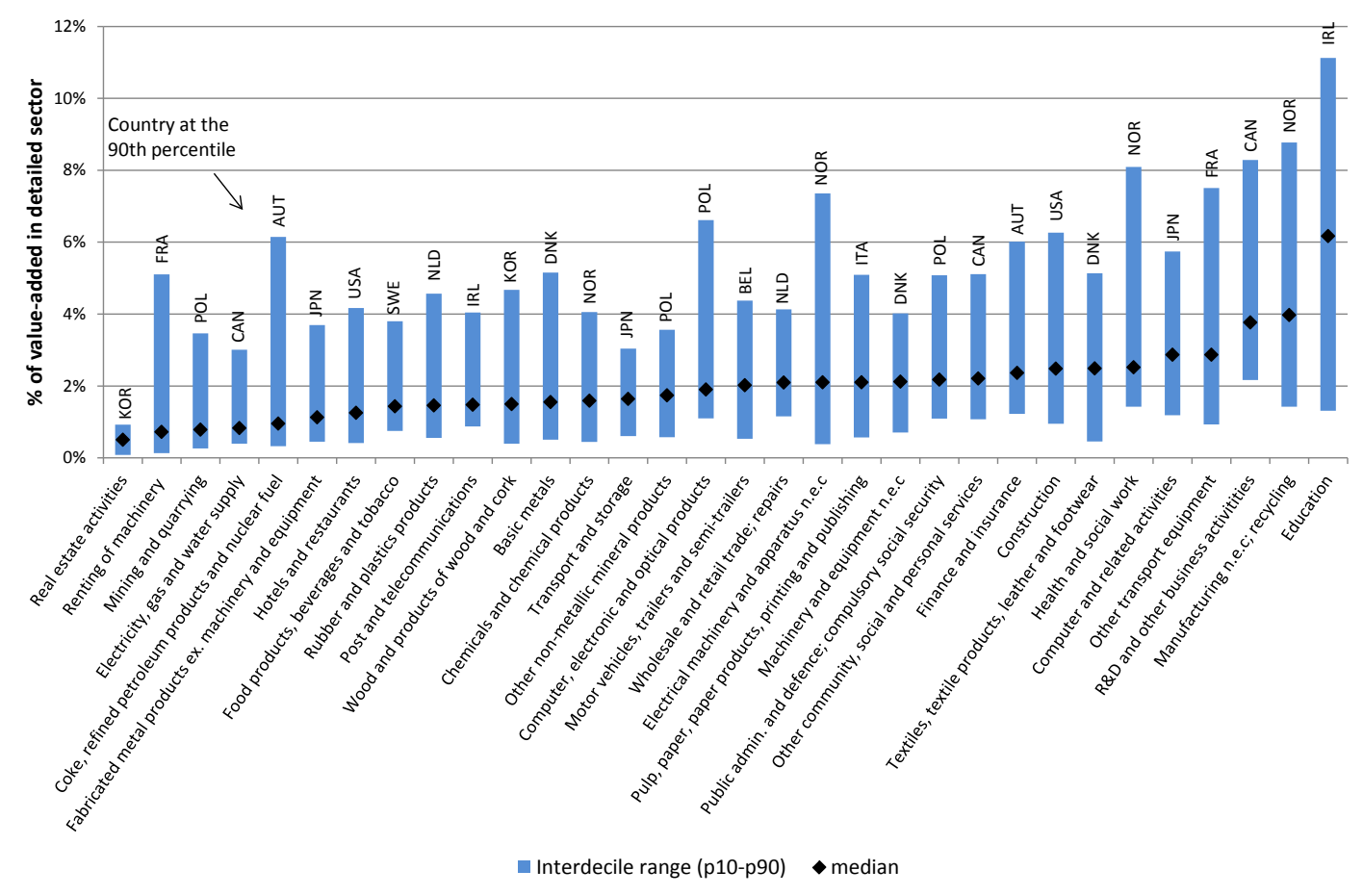

Source: OECD (2015).

\section{Organisational capital in the public sector}

Despite the importance of the non-market (or public) sector in many OECD economies, KBC investment in general and $O C$ investment in particular in this sector have received little attention. Ongoing research undertaken in the context of the SPINTAN project aims to fill this gap by estimating KBC investments for this sector of the economy (Corrado et al. 2014) and by addressing the differences that may exist in the nature of many intangible assets in relation to whether they are produced for use by the private or the public sector.

In the case of organisational capital, while its purpose might differ according to whether sustained competitive advantage is an objective or not, the more general nature of 
organisational knowledge remains comparable in both the public and private sectors. Indeed, the continued ability of workers to work together to produce output, be it sold at market prices or not, requires organisational know-how, team-building and communication. Hence, the taskbased definition of $\mathrm{OC}$ can be applied in the context of the public sector without further modification, and OC-related occupations can be identified as those who perform organisational tasks at a comparatively high level, as done in the case of the private sector.

OC investment in the public and private sectors is thus estimated using the same methodology as detailed above. Results are shown in Figure 7 and the sectoral breakdown follows the definition of non-market industries proposed by Corrado et al. (2014). The public sector refers to public entities, as reported in the PIAAC data, operating in ISIC revision 3 sectors 73 and 75 to 93. The private sector refers to private entities operating in the business sector (ISIC revision 3 codes 01 to 72 and 74 ).

With the exception of Belgium and the Netherlands, investment in OC, as a share of valueadded, is higher in public entities in the public sector than in private entities in the private sector. This is largely driven by non-managerial occupations, such as health and education professionals, that form a large share of employment in the public sector.

Figure 7.0C investment in the public and private sectors, 2012

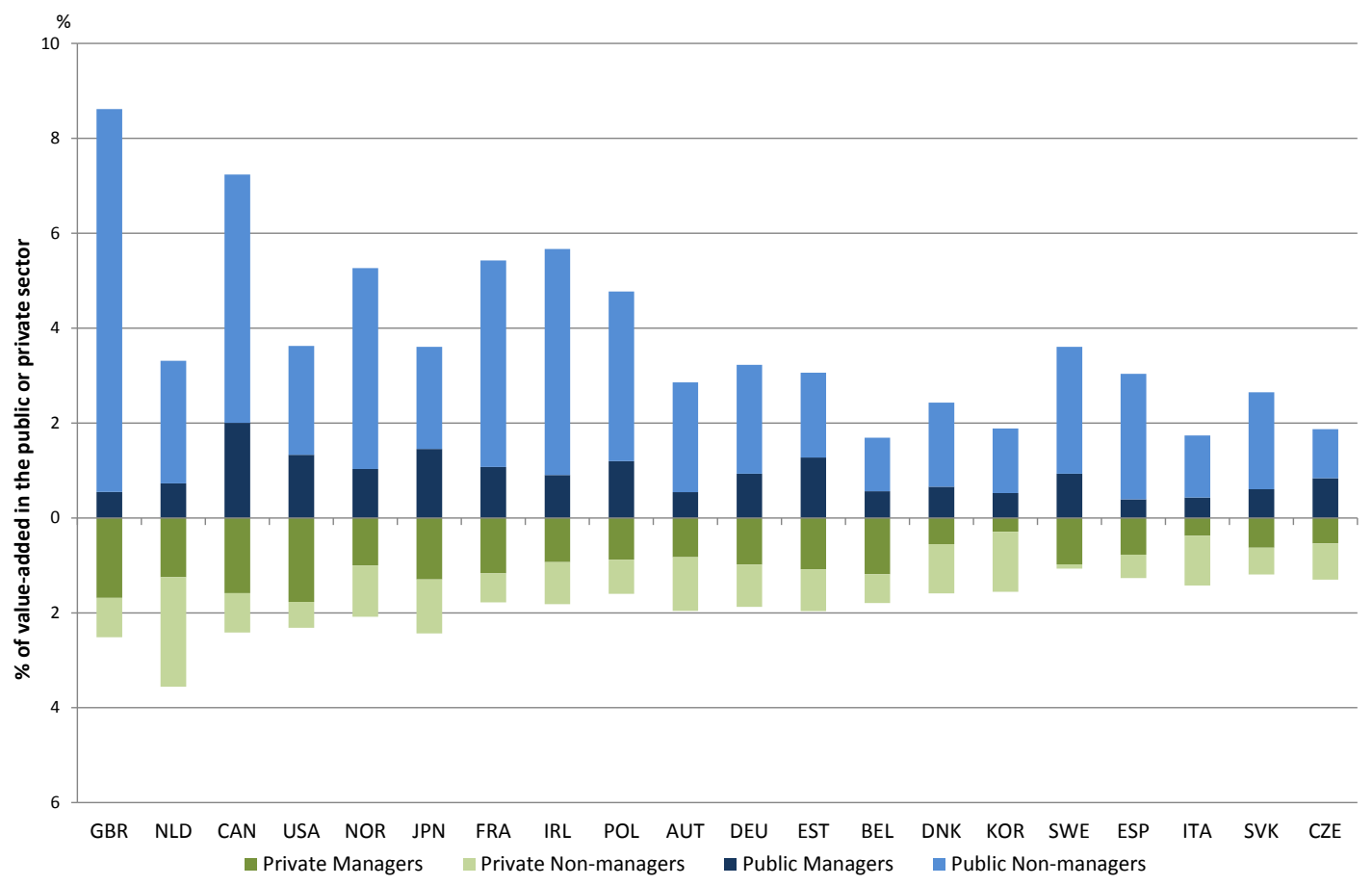

Source: OECD (2015).

Legend: Countries are sorted in descending order of $\mathrm{OC}$ investment intensity for the total economy, as in Figure 2. 


\section{Conclusions}

The present work proposes a definition of organisational capital and a measurement approach that builds on the organisational, management and economics literatures and is operationalised using novel cross-country data collected by the OECD PIAAC survey. It capitalises on the taskbased approach first proposed in Squicciarini and Le Mouel (2012), who use data from O*NET to calculate investment in $\mathrm{OC}$ at macro and 2-digit sectoral levels for the United States.

Organisational capital is defined as the firm-specific human capital performing a set of tasks affecting the medium and long-term functioning of firms, including developing objectives and strategies; organising, planning and prioritising work; building teams, matching employees to tasks, and providing training; supervising and coordinating activities; and communicating across and within groups to provide guidance and motivation.

The task-based methodology is implemented on the PIAAC data covering 20 countries and consists in combining the ranking of occupations according to the frequency with which they perform OC-related tasks, with a clustering analysis of occupations summarising all activities carried out at work. Results suggest that on average 20 broad occupational classes of the International Standard Classification of Occupations (ISCO 2008) are identified as OC-related in each country. This varies across countries and spans from 14 occupations in Korea to 24 occupations in Poland, supporting the hypothesis of cross-country heterogeneity in OC. Despite these differences, a core group of managerial occupations are consistently identified as OC occupations across countries. Differences arise in the selection of professionals and associate professionals in science and engineering, health, education, and business administration.

OC-related employment and investment figures for the year 2012 are estimated using the labour force participation and earnings information contained in the PIAAC survey. This is done following existing definitions of own-account investment in OC (especially from CHS), whereby $20 \%$ of the earnings of OC-related occupations is considered own-account investment in OC. At the aggregate level, the share of all OC occupations in total employment represents between $9.5 \%$ in Denmark to $26 \%$ in the United Kingdom, with an average of $16 \%$. Total investment in OC, as a share of value-added, ranges from $1.4 \%$ in the Czech Republic to $3.7 \%$ in the United Kingdom, with an average $2.2 \%$ across all countries. Splitting the share attributable to managers from that attributable to non-managerial OC occupations reveals that managers account for less than half of total employment and investment in OC. This suggests that measuring OC by looking only at managers is likely to lead to an underestimation of the resources devoted to OC.

The wealth of information contained in the PIAAC database allows for a detailed breakdown of OC employment and investment. We find that for most countries considered, total investment in $O C$ is higher in services than in manufacturing, in line with the industrial structure of the economy. We also find that in the services sector, small firms account for on average half of OC investment in that sector, while in manufacturing, $45 \%$ of OC investment comes from large firms. Finally, we look at the importance of OC investment in the public sector and find that, with only few exceptions, investment in $\mathrm{OC}$ is higher in the public sector than in the private sector. 
These estimates however need to be taken as such, as a number of underlying assumptions still need to be validated. Firstly, detailed time use surveys would provide important evidence to support the CHS assumption used to convert OC employment into investment. Indeed, it is likely that the amount of time spent on activities contributing to the long-term functioning of firms differs between occupations and that the $20 \%$ capitalisation factor does not apply homogenously. Secondly, the information on the occupational category of survey respondents is provided at a relatively aggregated level. A more detailed breakdown of this information would allow for a finer understanding of who contributes to the generation and accumulation of OC. Both of these limitations are likely to result in an overestimation of the amount of own-account OC investment undertaken in the economy.

Conversely, the estimates presented in this paper offer only a partial picture of OC investment, as firms dedicate important resources to purchasing organisational knowledge from external sources, especially the management consulting industry. CHS (2005) find that in the United States, the purchased component of OC investment represented around $25 \%$ of total OC investment for the period 1998-2000.

As investment in other KBC assets can also be estimated on the basis of labour cost information, special attention should be paid to avoid double-counting the time (and hence the cost) of employees working on tasks related to several KBC assets at the same time. The existence of clear complementarities between assets has been confirmed by several studies in the past, in particular between organisational capital and ICT or computerised information (e.g. Bresnahan et al., 2002). Overlaps in employment and complementarities between R\&D, OC, design and computerised information have also been explored in OECD (2013). Future work will therefore need to address complementarities and double counting issues, especially when expenditurebased approaches are pursued.

These results bring a new perspective on the importance of $\mathrm{OC}$ in the economy. They highlight large country and sectoral differences in the intensity of $O C$ investment, which have not yet been documented. In addition, the role of $\mathrm{OC}$ in economic growth, as evidenced in previous growth accounting exercises, would need to be revised to take into account the size of OC investment once non-managerial OC-related occupations are included. Finally, these updated estimates of OC investment can be used to analyse its role with respect to skill use and mismatch, its impact on the routinisation of tasks and resulting polarisation of wage distribution, and its role in integrating and upgrading global value chains (GVC). 


\section{APPENDIX}

Table A1. List of tasks present in PIAAC database

\begin{tabular}{|c|c|c|c|c|}
\hline $\begin{array}{l}\text { Task } \\
\text { code }\end{array}$ & Task description & $\begin{array}{c}\text { Robustness } \\
\text { check } 1 \\
4 \text { tasks } \\
\end{array}$ & $\begin{array}{c}\text { Main } \\
\text { analysis } \\
9 \text { tasks } \\
\end{array}$ & $\begin{array}{c}\text { Robustness } \\
\text { check } 2 \\
11 \text { tasks } \\
\end{array}$ \\
\hline & General tasks & & & \\
\hline 10 & Cooperating and collaborating with co-workers & & $\sqrt{ }$ & \\
\hline 11 & Sharing work-related information with co-workers & & $\sqrt{ }$ & $\sqrt{ }$ \\
\hline 12 & Instructing, training or teaching people, individually or in groups & $\sqrt{ }$ & $\sqrt{ }$ & $\sqrt{ }$ \\
\hline 13 & Making speeches or giving presentations in front of 5 or more people & & & \\
\hline 14 & Selling a product or a service & & & \\
\hline 15 & Advising people & & & $\sqrt{ }$ \\
\hline 16 & Planning your own activities & $\sqrt{ }$ & $\sqrt{ }$ & $\sqrt{ }$ \\
\hline 17 & Planning the activities of others & $\sqrt{ }$ & $\sqrt{ }$ & $\sqrt{ }$ \\
\hline 18 & Organising your own time & $\sqrt{ }$ & $\sqrt{ }$ & $\sqrt{ }$ \\
\hline 19 & Persuading or influencing people & & & $\sqrt{ }$ \\
\hline 20 & Negotiating with people either inside or outside your firm or organisation & & $\sqrt{ }$ & $\sqrt{ }$ \\
\hline 21 & Faced with simple problems that take no more than 5 minutes to find a good solution & & $\sqrt{ }$ & $\sqrt{ }$ \\
\hline 22 & Faced with complex problems that take at least 30 minutes to find a good solution & & $\sqrt{ }$ & $\sqrt{ }$ \\
\hline 23 & Working physically for a long period & & & \\
\hline \multirow[t]{2}{*}{24} & Using skill or accuracy with your hands or fingers & & & \\
\hline & Literacy, numeracy and ICT skill use at work & & & \\
\hline 25 & Read directions or instructions & & & \\
\hline 26 & Read letters, memos or emails & & & \\
\hline 27 & Read articles in newspapers, magazines, or newsletters & & & \\
\hline 28 & Read articles in professional journals or scholarly publications & & & \\
\hline 29 & Read books & & & \\
\hline 30 & Read manuals or reference materials & & & $\sqrt{ }$ \\
\hline 31 & Read bills, invoices, bank statements or other financial statements & & & \\
\hline 32 & Read diagrams maps or schematics & & & \\
\hline 33 & Write letters memos or emails & & & \\
\hline 34 & Write articles for newspapers, magazines or newsletters & & & \\
\hline 35 & Write reports & & & \\
\hline 36 & Fill in forms & & & \\
\hline 37 & Calculating prices, costs or budgets & & & \\
\hline 38 & Using or calculating fractions, decimals or percentages & & & \\
\hline 39 & Use a calculator, either hand-held or computer based & & & \\
\hline 40 & Prepare charts, graphs or tables & & & \\
\hline 41 & Use simple algebra or formulas & & & \\
\hline & Use advanced math or statistics such as calculus, complex algebra, trigonometry or & & & \\
\hline 42 & use of regression techniques & & & \\
\hline 43 & Use a computer for email & & & \\
\hline 44 & Use the internet to better understand issues related to your work & & & \\
\hline 45 & Conduct transactions on the internet & & & \\
\hline 46 & Use spreadsheet software & & & \\
\hline 47 & Use a word processor & & & \\
\hline 48 & Use a programming language to program or write computer code & & & \\
\hline 49 & Participate in real-time discussions on the internet & & & \\
\hline
\end{tabular}

Source: Authors' own calculations based on PIAAC data, extracted June 2015. 
Figure A1. Distribution of average answers by occupation
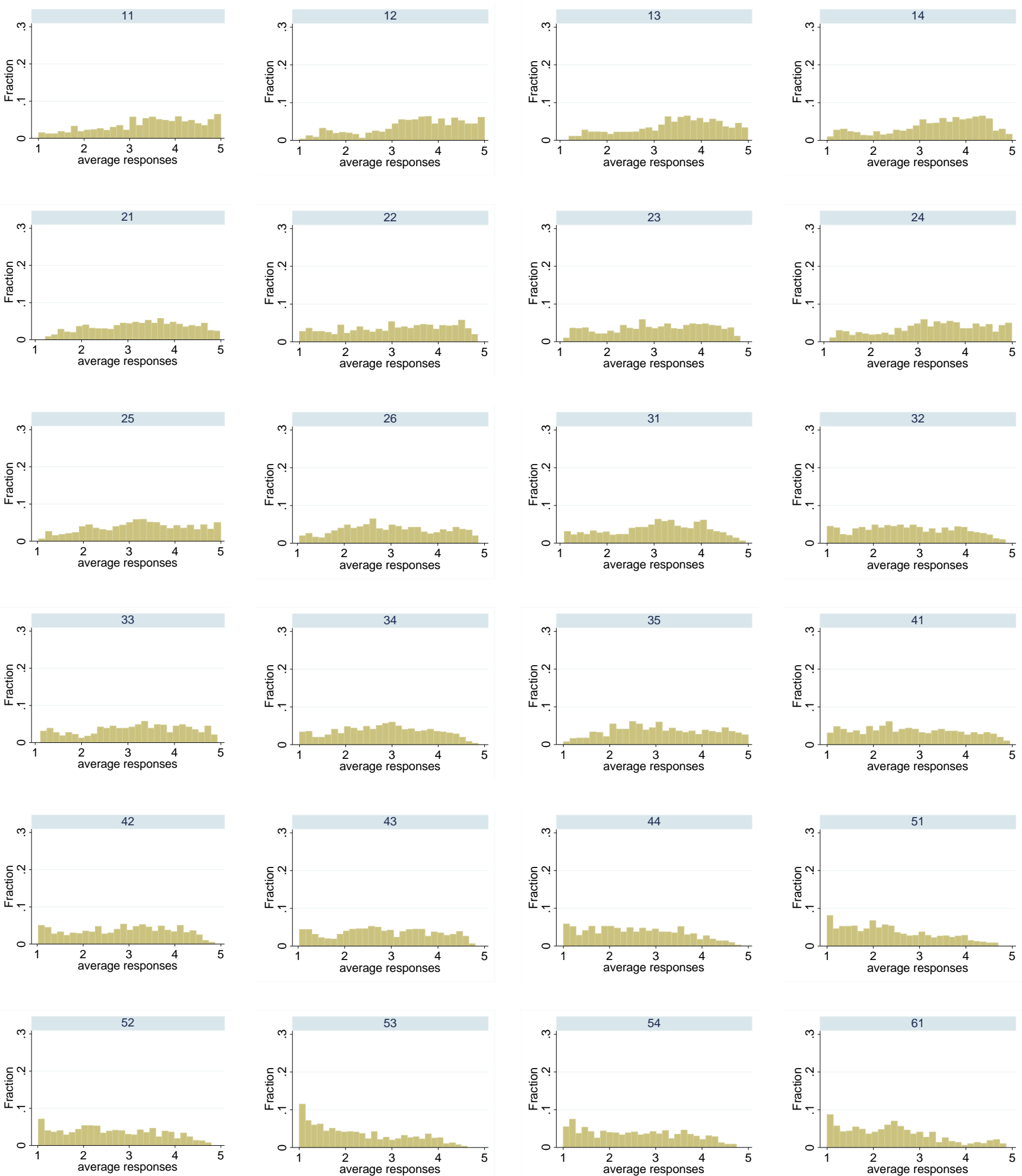

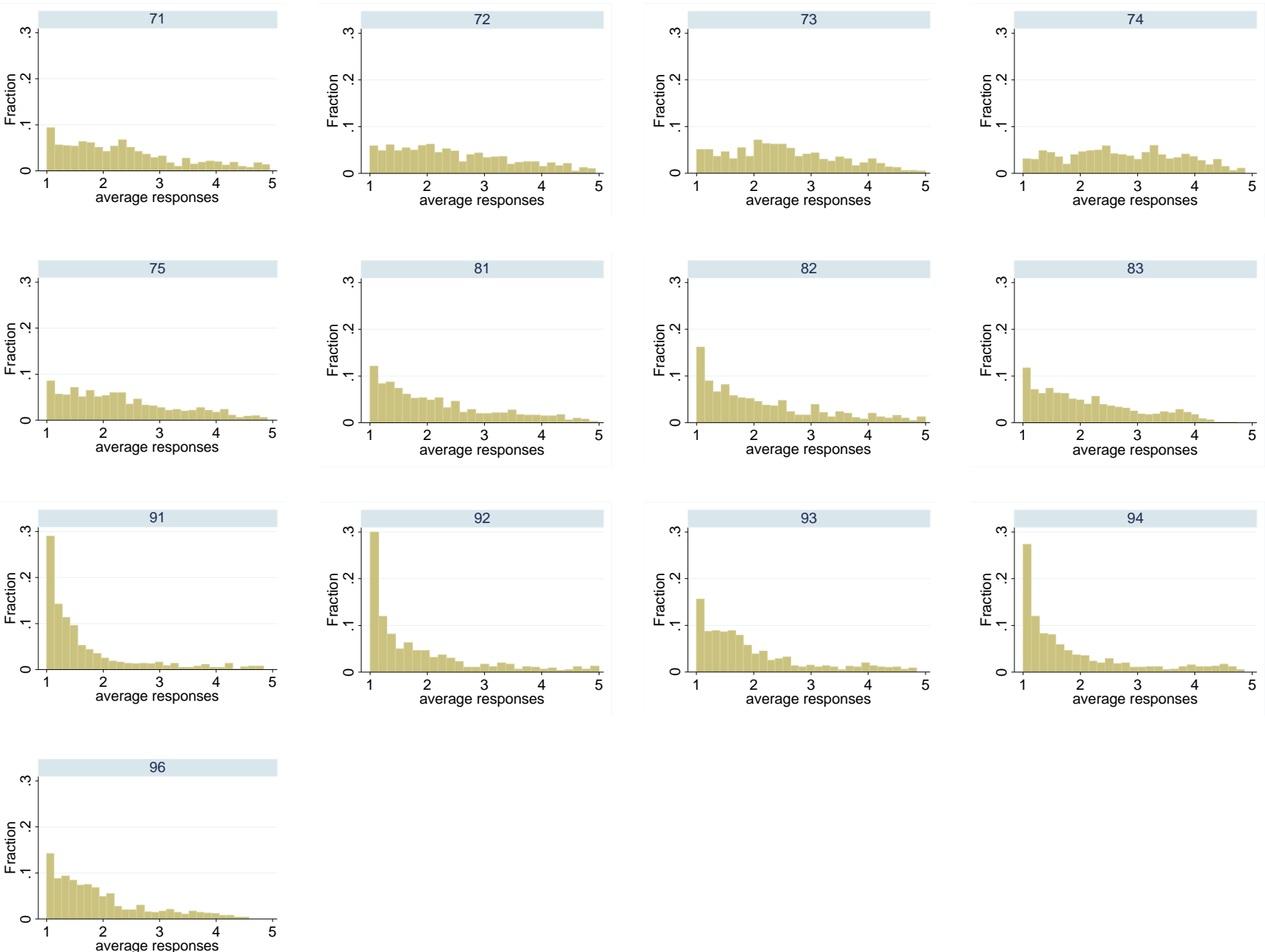

Source: Authors' own calculations based on PIAAC data, extracted June 2015. 
Table A2. Selection of OC-related occupations according to the PIAAC and to the ONET databases

\begin{tabular}{|c|c|c|c|}
\hline $\begin{array}{l}\text { ISCO } 3 \\
\text { digit }\end{array}$ & ISCO Title & ONET & PIAAC \\
\hline 110 & Chief executives and legislators & $\sqrt{ }$ & $\sqrt{ }$ \\
\hline 121 & Business services and administration managers & $\sqrt{ }$ & $\sqrt{ }$ \\
\hline 122 & Sales, marketing and development managers & $\sqrt{ }$ & $\sqrt{ }$ \\
\hline 131 & Production managers in agriculture & & $\sqrt{ }$ \\
\hline 132 & Manufacturing, mining, construction, and distribution managers & $\sqrt{ }$ & $\sqrt{ }$ \\
\hline 133 & Information and communications technology service managers & $\sqrt{ }$ & $\sqrt{ }$ \\
\hline 134 & Professional services managers & $\sqrt{ }$ & $\sqrt{ }$ \\
\hline 141 & Hotel and restaurant managers & $\sqrt{ }$ & $\sqrt{ }$ \\
\hline 142 & Retail and wholesale trade managers & $\sqrt{ }$ & $\sqrt{ }$ \\
\hline 143 & Other services managers & $\sqrt{ }$ & $\sqrt{ }$ \\
\hline 213 & Life science professionals & $\sqrt{ }$ & \\
\hline 214 & Engineering professionals (excluding electrotechnology) & $\sqrt{ }$ & \\
\hline 216 & Architects, planners, surveyors and designers & $\sqrt{ }$ & \\
\hline 220 & Health professionals, except doctors & $\sqrt{ }$ & $\sqrt{ }$ \\
\hline 221 & Medical doctors & $\sqrt{ }$ & $\sqrt{ }$ \\
\hline 232 & Vocational education teachers & & $\sqrt{ }$ \\
\hline 233 & Secondary education teachers & & $\sqrt{ }$ \\
\hline 234 & Pre- and primary school teachers & & $\sqrt{ }$ \\
\hline 242 & Administration professionals & $\sqrt{ }$ & \\
\hline 243 & Sales, marketing and public relations professionals & $\sqrt{ }$ & \\
\hline 252 & Database and network professionals & $\sqrt{ }$ & \\
\hline 261 & Legal professionals & & $\sqrt{ }$ \\
\hline 262 & Librarians, archivists and curators & $\sqrt{ }$ & \\
\hline 263 & Social and religious professionals & $\sqrt{ }$ & $\sqrt{ }$ \\
\hline 312 & Mining, manufacturing and construction supervisors & $\sqrt{ }$ & $\sqrt{ }$ \\
\hline 322 & Nursing and midwifery & & $\sqrt{ }$ \\
\hline 331 & Financial and mathematical associate professionals & $\sqrt{ }$ & \\
\hline 334 & Administrative and specialised secretaries & $\sqrt{ }$ & \\
\hline 343 & Artistic, cultural and culinary associate professionals & $\sqrt{ }$ & \\
\hline 522 & Shop salespersons & $\sqrt{ }$ & \\
\hline
\end{tabular}

Source: Authors' own calculations based on PIAAC data, extracted June 2015, and O*NET data (version 16.0), extracted April 2012 


\section{REFERENCES}

Agterberg, M, B. van den Hoof, M. Huysman and M. Soekijad (2010), "Keeping the Wheels Turning: The Dynamics of Managing Networks of Practice" Journal of Management Studies, Vol. 47(1): 85-108.

Allen, D (2006), "Do Organizational Socialization Tactics Influence Newcomer Embeddedness and Turnover?" Journal of Management, Vol. 32(2): 237-256.

Allen, J., M. Levels and R. van der Velden (2013). "Skill mismatch and use in developed countries: Evidence from the PIAAC study." Maastricht University, Research Centre for Education and the Labour Market, RM/13/061

van Alstyne, M. (1997), "The State of Network Organization: A Survey in Three Frameworks" Journal of Organizational Computing and Electronic Commerce, Vol. 7(2/3): 83-151.

Aral, S. and P. Weill (2007). "IT Assets, Organisational Capabilities, and Firm Performance: How Resource Allocations and Organisational Differences Explain Performance Variation." Organisation Science. 18(5): 763-780.

Atkeson, A. and P. J. Kehoe, (2005), "Modeling and Measuring Organisation Capital", Journal of Political Economy, Vol. 113(5): 1026-1053.

Bailey, T, P. Berg, and C. Sandy, (2001), "The Effect of High-Performance Work Practices on Employee Earnings in the Steel, Apparel and Medical Electronics and Imagery Industries", Industrial and Labor Relations Review, Vol. 54, No. 2A, Extra Issue: Industry Studies of Wage Inequality (Mar., 2001), pp. 525-543.

Birkinshaw, J. andP. Hagstrom, (2000), The Flexible Firm: Capability Management in Network Organizations, Oxford University Press on Demand.

Black, S. and L. Lynch, (2001), "How to Compete: The Impact of Workplace Practices and Information Technology on Productivity", Review of Economics and Statistics, 83(3): 43445

Black, S., and L. Lynch (2005). "Measuring Organisational Capital in the New Economy." in C. Corrado, J. Haltiwanger and D. Sichel (eds). Measuring Capital in a New Economy. National Bureau of Economic Research and University of Chicago Press.

Black, S, L. Lynch, and A. Krivelyova, (2004), "How Workers Fare when Employers Innovate", Industrial Relations, Vol. 43 (1): 44-66.

Bloom, N., C. Genakos, R. Sadun and J. Van Reenen, (2012), "Management Practices across Firms and Countries", National Bureau of Economic Research Working Paper No. 17850, February 2012.

Bloom, N. and J. Van Reenen, (2007), "Measuring and Explaining Management Practices Across Firms and Countries", Quarterly Journal of Economics, 122(4): 1351-1408.

Bloom, N., and J. Van Reenen (2010). "Why Do Management Practices Differ across Firms and Countries?" Journal of Economic Perspectives, 24(1): 203-224. 
Borgatti S and P. Foster (2003), "The Network Paradigm in Organizational Research: A Review and Typology", Journal of Management, 29(6):991-1013.

Bounfour, A. (2010), Le Capital Organisationnel : Principes, Enjeux, Valeur, Springer-Verlag, Paris, France.

Brynjolfsson, E., Hitt, L. M., and S. Yang (2002). "Intangible Assets: Computers and Organisational capital." Brookings Papers on Economic Activity, 1:137-198.

Caroli, E, and J. Van Reenen, (2001), "Skill-Biased Organisational Change? Evidence from a Panel of British and French Establishments", Quarterly Journal of Economics Vol. 116, No. 4 (Nov., 2001), pp. 1449-1492.

Che, N.X. (2009), "Sectoral Structural Change in a Knowledge Economy" MPRA Paper.

Clinton M, T. Knight and D. Guest, (2012), "Job Embeddedness: a New Attitudinal Approach" International Journal of Selection and Assessment, 20(1):111-117.

Cohen, L. E., (2013), "Assembling Jobs: A Model of How Tasks Are Bundled Into and Across Jobs" Organization Science. 24(2) 432-454

Corrado, C., C. Hulten, and D. Sichel, (2005), "Measuring Capital and Technology: An Expanded Framework." in C. Corrado, J. Haltiwanger and D. Sichel (eds), Measuring Capital in a New Economy, National Bureau of Economic Research and University of Chicago Press.

Corrado, C., C. Hulten, and D. Sichel. (2009), "Intangible Capital and US Economic Growth" Review of Income and Wealth, 55(3) 661-685.

Corrado, C., J. Haskel, and C. Jona-Lasinio, (2014) "Smart Public Intangibles: SPINTAN Framework and Measurement Guidelines", SPINTAN Project: Smart Public intangibles Publication, project funded from the EU's $7^{\text {th }}$ Framework Programme for research, technological development and demonstration under grant agreement no: 612774

Duda, R. O. and P. E. Hart. (1973). Pattern Classification and Scene Analysis. Wiley and Son, New York.

Evenson R. E. and L. E. Westphal, (1995), "Technological Change and Technology Strategy" in Jere Behrman and T.N. Srinivasan, Handbook of Development Economics, Elsevier, Vol(3) 2209-2299

Grant, R. M., (1996), "Toward a knowledge-based theory of the firm" Strategy Management Journal, 17: 109-122. doi: 10.1002/smj.425017111

Greenan, N., (2012), "Measuring learning organisations", Presentation given at the OECD Expert Meeting on the Measurement of Intangible Assets, Paris, 22-23 March 2012.

Gulati R. (1998), "Alliances and Networks", Strategic Management Journal, Vol. 19(4): 293-317.

Gulati R. (2007), Managing Network Resources: Alliances, Affiliations, and Other Relational Asset, New York: Oxford University Press.

Hales, C. (2002), "'Bureaucracy-lite' and Continuities in Managerial Work", British Journal of Management, 13(1): 51-66. 
Hansen, G. S., and B. Wernerfelt (1989). "Determinants of Firm Performance: The Relative Importance of Economic and Organisational Factors." Strategic Management Journal, 10: 399-411. doi: 10.1002/smj.4250100502

Hanushek, E., G. Schwerdt, S. Wiederhold, and L. Woessmann, (2015) "Returns to skills around the world: Evidence from PIAAC", European Economic Review, 73(1):103-130.

Hayton J, G. Carbunaci and R. Eisenberger, (2012), "With a Little Help from my Colleagues: A Social Embeddedness Approach to Perceived Organizational Support", Journal of Organizational Behaviour, volume 33, issue 2, 235-249.

International Labour Office (ILO). The International Standard Classification of Occupations (ISCO), http://www.ilo.org/public/english/bureau/stat/isco/ (last accessed October 2014).

Johnson, W. (1999), "An Integrative Taxonomy of Intellectual Capital: Measuring the Stock and Flow of Intellectual Capital Components of the Firm", International Journal of Technology Management, Volume 18, numbers 5-8, 562-575.

Jovanovic, B. (1979), "Job Matching and the Theory of Turnover", Journal of Political Economy, 87(5): 972-990.

Kaplan, S. N., Klebanov, M. M. and M. Sorensen. (2012). "Which CEO Characteristics and Abilities Matter?" The Journal of Finance. 67(3)973-1007.

Kapoor, R., and R. Adner, (2011), "What Firms Make vs. What They Know: How Firms' Production and Knowledge Boundaries Affect Competitive Advantage in the Face of Technological Change", Organization Science, 23(5): 1227-1248.

von Krogh, G., Nonaka, I. and Rechsteiner, L. (2012), "Leadership in Organizational Knowledge Creation: A Review and Framework" Journal of Management Studies, 49: 240-277.

Lev, B., and S. Radhakrishnan, (2005), "The Valuation of Organization Capital", in C. Corrado, J. Haltiwanger and D. Sichel (eds), Measuring Capital in a New Economy, National Bureau of Economic Research and University of Chicago Press.

Lev, B, S. Radhakrishnan and W. Zhang, (2009), "Organisation Capital" Abacus, Vol. 45, No. 3

Lounsbury, M and M. Ventresca, (2003), "The New Structuralism in Organizational Theory", Organization, Volume 10(3).

Ludwig , O, and D. Sadowski, (2009), "Measuring Organisational Capital" Schmalenback Business Review 61: 393-412.

Meyer, K, R. Mudambi and R. Narula, (2011), "Multinational Enterprises and Local Contexts: The Opportunities and Challenges of Multiple Embeddedness", Journal of Management Studies, 48(2) 235-252.

Miyagawa T, K. Lee, and S Kabe, (2010), "Management Practices and Firm Performance in Japanese and Korea Firms. An Empirical Study Using Interview Surveys", Conference of the Chaire européenne de management de l'immatériel, Université de Paris-Sud, 15 Mars 2010. 
Miyagawa, T, and Y. Kim, (2008), "Measuring Organisation Capital in Japan: An Empirical Estimate Using Firm-level Data", Seoul Journal of Economics, volume 21.

Moran, P. (2005), "Structural vs. relational embeddedness: social capital and managerial performance." Strategy of Management Journal, 26: 1129-1151. doi: 10.1002/smj.486

Ng, T. W. H., and D. C. Feldman, (2009), "How Broadly does Education Contribute to Job Performance?" Personnel Psychology. 62(1) 89-134.

Nocke, V. and Yeaple, S. (2014), "Globalization and multiproduct firms" International Economic Review, 55: 993-1018. doi: 10.1111/iere.12080

Nonaka, I., (1994), "A Dynamic Theory of Organizational Knowledge Creation" Organization Science 5(1):14-37

Organisation for Economic Co-operation and Development (OECD). Programme for the International Assessment of Adult Competencies (PIAAC), http://www.oecd.org/site/piaac/surveyofadultskills.htm (last accessed June 2015).

Organisation for Economic Co-operation and Development (OECD), 2013. "Defining and Measuring Organisational Capital, R\&D, Design and Computerised Information: a Human Capital-Based Approach", OECD/STI internal document DSTI/EAS/IND/WPIA(2013)2.

OECD (2015), OECD Science, Technology and Industry Scoreboard 2015, OECD Publishing, Paris. DOI: http://dx.doi.org/10.1787/sti scoreboard-2015-en

Papanikolaou D., and A. Eisfeldt (2009), "Organisation Capital and the Cross-Section of Expected Returns." Society for Economic Dynamics. Meeting Papers 671.

Pellizzari, M. and A. Fichen (2013). "A New Measure of Skills Mismatch: Theory and Evidence from the Survey of Adult Skills (PIAAC)." OECD Social, Employment and Migration Working Papers, No. 153, OECD Publishing. DOI: 10.1787/5k3tpt04lcnt-en

Ployhart, R. E., and T. P. Moliterno. (2011). “Emergence of the Human Capital Resource: A Multilevel Model". Academy of Management Review. 38(1) 127-150.

Prescott, E., and M. Visscher (1980). "Organisation Capital." Journal of Political Economy. 88(3) 446-461.

Rosen, S. (1972), "Learning by Experience as Joint Production", Quarterly Journal of Economics, 86 (3): $366-82$.

SPINTAN, "Smart Public INTANgibles", www.spintan.net

Squicciarini, M., and M. Le Mouel (2012). “Defining and Measuring Investment in Organisational Capital: Using US Microdata to Develop a Task-based Approach." OECD Science, Technology and Industry Working Papers 2012/5, OECD Publishing.

Squicciarini, M., L. Marcolin, and P. Horvát (2015). “Estimating cross-country investment in training:

an experimental methodology using PIAAC data." OECD Science, Technology and Industry Working Papers, DOI:10.1787/18151965 . 
Teece, D, G, Pisano and A, Shuen, (1997), "Dynamic Capabilities and Strategic Management" Strategic Management Journal, 18(7):509-533. 